\title{
Natural product-based nanomedicine: recent advances and issues
}

This article was published in the following Dove Press journal:

International Journal of Nanomedicine

28 September 2015

Number of times this article has been viewed

\section{Rebekah Watkins ${ }^{1,2, *}$ \\ Ling $\mathrm{Wu}^{1, *}$ \\ Chenming Zhang ${ }^{3-5}$ \\ Richey M Davis $3,5,6$ \\ Bin $X u^{1,3}$}

'Department of Biochemistry, ${ }^{2}$ Program in Nanoscience, ${ }^{3}$ Center for Drug Discovery, ${ }^{4}$ Department of Biological Systems Engineering, ${ }^{5}$ Institute for Critical Technology and Applied Science, ${ }^{6}$ Department of Chemical Engineering, Virginia Polytechnic Institute and State University, Blacksburg, VA, USA

*These authors contributed equally to this work
Correspondence: Bin Xu

Department of Biochemistry and Center for Drug Discovery, Virginia Polytechnic Institute and State University, 105 Engel Hall, Blacksburg, VA 2406I, USA

$\mathrm{Tel}+\mid 54023$ | |449

$\mathrm{Fax}+|54023| 9070$

Email binxu@vt.edu
Abstract: Natural products have been used in medicine for many years. Many top-selling pharmaceuticals are natural compounds or their derivatives. These plant- or microorganismderived compounds have shown potential as therapeutic agents against cancer, microbial infection, inflammation, and other disease conditions. However, their success in clinical trials has been less impressive, partly due to the compounds' low bioavailability. The incorporation of nanoparticles into a delivery system for natural products would be a major advance in the efforts to increase their therapeutic effects. Recently, advances have been made showing that nanoparticles can significantly increase the bioavailability of natural products both in vitro and in vivo. Nanotechnology has demonstrated its capability to manipulate particles in order to target specific areas of the body and control the release of drugs. Although there are many benefits to applying nanotechnology for better delivery of natural products, it is not without issues. Drug targeting remains a challenge and potential nanoparticle toxicity needs to be further investigated, especially if these systems are to be used to treat chronic human diseases. This review aims to summarize recent progress in several key areas relevant to natural products in nanoparticle delivery systems for biomedical applications.

Keywords: natural products, nanomedicine, drug delivery, bioavailability, targeting, controlled release

\section{Introduction}

Natural products have been used as herbal medicines throughout human history. Today, approximately one-third of the top-selling pharmaceuticals are natural products or their derivatives. ${ }^{1-3}$ Although many of the drugs used today come from natural products, major pharmaceutical companies have not paid due attention to these compounds for a variety of reasons. The lack of attention could be due to the outdated idea that natural products are only useful as antibiotics: natural products had huge success in the post-World War II era as antibiotics, and the two terms have become synonymous. ${ }^{1}$ While large pharmaceutical companies have favored screening synthetic compound libraries for drug discovery, small companies have started to explore natural products' uses against cancer, microbial infection, inflammation, and other diseases. ${ }^{4,5}$ The biggest issue with the use of natural products in disease treatment is their low bioavailability, which has caused problems in clinical trials. ${ }^{5}$ Subjects taking curcumin orally, eg, required doses of $3.6 \mathrm{~g} /$ day to obtain serum levels of $11.1 \mathrm{nmol} / \mathrm{L}$. Patients who received lower doses of curcumin did not have detectable plasma levels. ${ }^{6,7}$ Results are similar for other common natural products, such as polyphenols and flavonoids. ${ }^{8,9}$

The use of nanotechnology has shown immense success in the field of drug delivery. The definition of a nanoparticle has been highly debated, and an internationally 
accepted definition has not been reached. Many sources define nanomaterials as particles of size ranging between $1 \mathrm{~nm}$ and $100 \mathrm{~nm} .{ }^{10}$ The definition of a nanomaterial, however, is more complicated than simply size. The benefits of nanotechnology are due to the range of properties and interactions that are unique to the nanoscale structure. ${ }^{10}$ Thus, particles $>100 \mathrm{~nm}$ can exhibit these unique properties and can be considered nanomaterials. For example, polymer nanoparticles between $10 \mathrm{~nm}$ and 1,000 $\mathrm{nm}$ in diameter can have the characteristics desired for a successful delivery system. ${ }^{5,11}$ The most common types of nanoparticles used for drug delivery are polymer nanoparticles, solid lipid nanoparticles (SLNs), crystal nanoparticles, liposomes, micelles, and dendrimers (Figure 1A). Each of these nanoparticles has its own advantages and disadvantages as drug delivery vehicle.

Polymeric nanoparticles have been the most tested in combination with natural products. Poly(lactic-co-glycolic acid) (PLGA), polyethylene glycol (PEG), polyvinyl alcohol (PVA), poly-L-lactic acid (PLA), polycaprolactone (PCL), and chitosan are the most common polymers used due to their biocompatibility, biodegradability, and the fact that they are easy to functionalize (Figure 1B). Chitosan itself is a natural polymer that has gained attention recently in applications with natural product delivery. ${ }^{12-18}$ There are two types of polymeric nanoparticles: nanocapsules and nanospheres (Figure 1C). Nanocapsules contain a drug-filled core, which is surrounded by a polymer membrane. The nanospheres are porous and the drug is uniformly distributed among the pores. ${ }^{19}$

Phospholipids comprise liposomes and some micelles (Figure 1A). Liposomes are composed of phospholipid bilayers similar to cell membranes, whereas micelles composed of phospholipids only have one layer in which the head group faces the outside and the hydrophobic tails form the micelle core in a hydrophilic environment, such as the blood. The type of nanoparticles used in a given delivery application can be selected based on the physicochemical properties of the drug of interest. For example, the liposomal aqueous compartment formed by the hydrophilic head groups of the phospholipids can contain one or more hydrophilic drugs. A lipophilic drug, however, is better suited for delivery with a micelle, in which the lipophilic tails of the phospholipids form the drug-containing compartment, ${ }^{20}$ although liposomes have also been used in cases in which the lipophilic drug dissolves into the liposomal bilayer. ${ }^{21}$ Liposomes have been formulated to show no adverse or toxic effects on healthy cells. ${ }^{22}$ Adjustments can also be made to the liposome size, surface charge, and number of lamellae. ${ }^{5}$
SLNs contain a solid hydrophobic core surrounded by phospholipids (Figure 1A). These nanoparticles are a good choice for hydrophobic drug delivery. SLNs are more stable than liposomes and, in some cases, are less toxic than polymeric nanoparticles. ${ }^{19}$ To overcome some limitations in the old-generation SLNs, liquid lipid has been incorporated into the solid structure, resulting in nanostructured lipid carriers (Figure 1D). Three types of lipid nanoparticles have been described: an imperfect type, an amorphous type, and a multiple type. ${ }^{23}$ The imperfect type contains spatially different lipids and allows for increased drugloading capacity. The amorphous type mixes solid lipids with special lipids, such as medium-chain triglycerides, to prevent crystallization and drug expulsion during storage. The multiple-type nanoparticle has added liquid lipids that increase the solubility of many drugs and decrease drug expulsion during storage.

The use of nanotechnology with natural products is a rapidly developing field. Nanotechnology brings multiple advantages to the delivery of natural compounds in the treatment of cancer and other chronic human diseases. The incorporation of nanoparticles can increase the bioavailability, targeting, and controlled-release profiles of the natural products. To our knowledge, only a few reviews with limited scopes have been published on natural product-centered nanotechnology. Past reviews have focused on the use of nanoparticles with curcumin, ${ }^{22,24,25}$ flavonoids, ${ }^{19}$ traditional Chinese medicine, ${ }^{26}$ and the synthesis and characterization of nanoparticles with natural products. ${ }^{5}$ In our review, we will address key aspects of natural product-based nanomedicine, including natural compounds, bioavailability, targeting, controlled release, and related challenges.

\section{Natural compounds}

Natural compounds, which are also called natural products, are complex chemical molecules found in plants and microorganisms. Some natural compounds have pharmacological or biological activities that provide therapeutic benefits in treating human diseases. Natural compounds have been studied and used for the treatment of cancer, infectious disease, and other various disease conditions in complementary and alternative medicine. This review will discuss a representative number of the most commonly studied natural compounds. This section will focus on natural compounds that have been studied in combination with nanoparticles and used as nanomedicine. In the past 30 years, the US Food and Drug Administration (FDA) and other regulatory agencies worldwide have approved $\sim 61 \%$ of the developed 


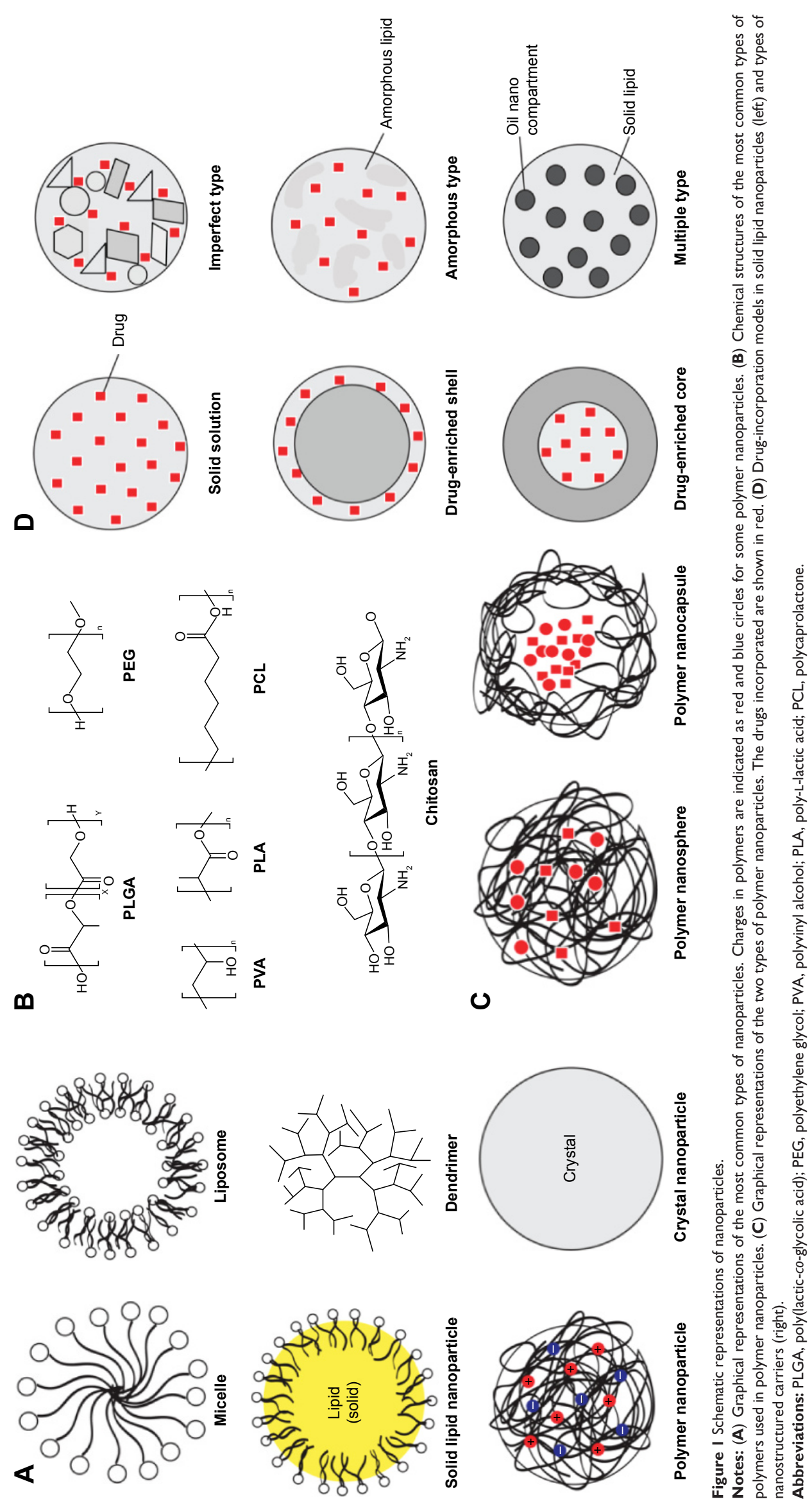


natural compounds to treat cancer and $49 \%$ of them to treat infections. ${ }^{27}$ The mechanisms of action of these natural compounds will also be reviewed. Structures of selected natural compounds discussed in this review are shown in Figure 2. Relevant physicochemical properties of the selected compounds are listed in Table 1.

\section{Application to cancer}

The use of natural compounds for cancer treatment has been extensively studied. Some natural compounds combat cancer by the induction of tumor-suppressing autophagy. This mechanism of action has been identified for $\sim 50$ different natural compounds. The most recognizable compounds are curcumin and caffeine. ${ }^{31,32} \mathrm{~A}$ few studies observed that curcumin is able to induce autophagy, which is associated with cell death..$^{33,34}$
Xiao et $\mathrm{al}^{35}$ found that curcumin induces autophagy in lung adenocarcinoma cells via the AMP-activated protein kinase signaling pathway but did not affect the healthy lung tissue. Caffeine has a different mechanism for inducing autophagy. Caffeine, with the addition of rapamycin, has been found to increase levels of autophagosomes by inhibiting the phosphoinositide 3-kinase, protein kinase B (also known as Akt), mammalian target of rapamycin (mTOR), and p70S6 kinase signaling. This is similar to the processes of several other anticancer agents, such as rapamycin, everolimus, and temsirolimus. ${ }^{36-38}$ Between 15 and 20 natural compounds have been shown to have cytoprotective autophagy characteristics. The most studied of these compounds is resveratrol, which has been shown to induce protective autophagy in both glioma and melanoma cells. ${ }^{32}$ Resveratrol has been shown to induce<smiles>O=C1CC(c2ccc(O)cc2)Oc2cc(O)cc(O)c21</smiles>

Apigenin<smiles>COc1ccc2c(c1OC)C=c1cc3c(cc1=CC2)CCO3</smiles>

Berberine

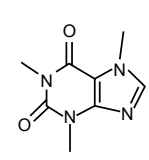

Caffeine<smiles>C[C@H]1C=C2c3nc4ccccc4cc3CN2C(=O)C2=C1CCC(=O)[C@]2(C)O</smiles>

Camptothecin<smiles>Cc1ccc(C(C)C)cc1O</smiles><smiles>Oc1cc(O)c2c(c1)O[C@H](c1ccc(O)c(O)c1)C(O)C2</smiles>

Catechin<smiles>O=C(CCOc1cc(O)cc(O)c1COCc1cc(O)c(O)c(O)c1)c1cc(O)c(O)c(O)c1</smiles>

Epigallocatechin gallate (EGCG)

Cinnamaldehyde

Coumarin-6

Curcumin

Ellagic acid<smiles>O=C1Oc2c(O)cc(O)c3c2c(=O)oc2c(O)c(O)cc1c23</smiles><smiles>C=CCc1ccc(OCCC)c(OC)c1</smiles>

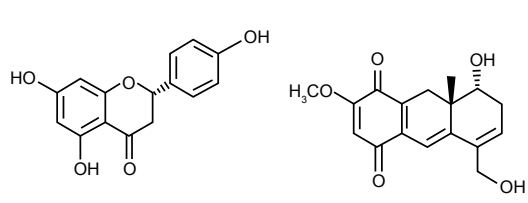

Naringenin

Oncocalyxone A

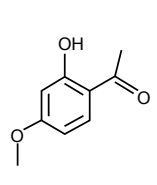

Paeonol<smiles>O=c1c(O)c(-c2ccc(O)cc2O)oc2cc(O)cc(O)c12</smiles>

Quercetin<smiles>Oc1ccc(C=Cc2cc(O)cc(O)c2)cc1</smiles>

Resveratrol<smiles>O=C(/C=C/c1ccc(O)c(O)c1)OC(=O)C(O)(CO)Cc1ccc(O)c(O)c1</smiles>

Rosmarinic acid<smiles>OC[C@H]1O[C@H](OCc2ccc(O)cc2)[C@H](O)[C@@H](O)[C@H]1O</smiles>

Salidroside

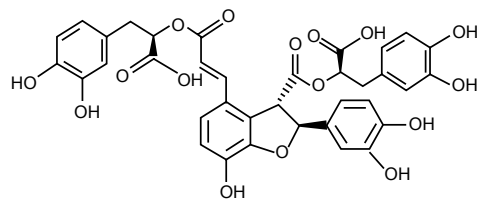

Salvianolic acid B<smiles>COc1cc([C@H]2Oc3cc([C@H]4Oc5cc(O)cc(O)c5C(=O)[C@H]4C)ccc3O[C@H]2CO)ccc1O</smiles>

Silibinin<smiles>O=C1c2c(O)cc(O)cc2O[C@H](c2ccc(O)c(O)c2)C1O</smiles>

Taxifolin<smiles>CC1=CC(=O)C(C(C)C)=CC1=O</smiles>

Thymoquinone

Figure 2 Chemical structures of selected natural compounds discussed in this review. 
Table I Physicochemical properties of selected natural compounds ${ }^{\mathrm{a}}$

\begin{tabular}{|c|c|c|}
\hline $\begin{array}{l}\text { Natural } \\
\text { compound }\end{array}$ & $\begin{array}{l}\text { Partition } \\
\text { coefficient } \\
(\text { logP) } \\
\end{array}$ & $\begin{array}{l}\text { Polar surface } \\
\text { area/molecular } \\
\text { surface area }\left(\AA^{2}\right)\end{array}$ \\
\hline Apigenin & 2.71 & $86.99 / 326.60$ \\
\hline Baicalein & 2.71 & $86.99 / 325.74$ \\
\hline Berberine & -1.28 & $40.8 / 473.39$ \\
\hline Caffeic acid & 1.53 & $77.76 / 226.17$ \\
\hline Caffeine & -0.55 & $58.44 / 269.15$ \\
\hline Catechin & 1.80 & I I 0.38/373.00 \\
\hline Cinnamaldehyde & 1.98 & I7.07//94.07 \\
\hline Curcumin & $4.12,3.29^{\mathrm{b}}$ & $93.06 / 509.73$ \\
\hline Epigalloctechin gallate & 3.08 & $197.37 / 556.67$ \\
\hline Ellagic acid & 2.32 & $133.52 / 319.89$ \\
\hline Epicatechin & 1.80 & I I0.38/373.0I \\
\hline Eugenol & 2.61 & $29.46 / 257.78$ \\
\hline Gambogic acid & 7.78 & $119.36 / 906.97$ \\
\hline Genistein & $3.08,3.04^{c}$ & $86.99 / 325.45$ \\
\hline 6-Gingerol & 3.62 & $66.76 / 507.44$ \\
\hline Hydroxytyrosol & 0.89 & $60.69 / 230.61$ \\
\hline Kaempferol & $2.46,3.1 I^{c}$ & 107.22/337.38 \\
\hline Luteolin & 2.40 & 107.22/337.39 \\
\hline Morin & 2.16 & I27.45/348.34 \\
\hline Naringenin & $2.84,2.6^{c}$ & $86.99 / 351.06$ \\
\hline Oleuropein & 0.11 & $201.67 / 727.25$ \\
\hline Paeonol & 1.72 & $46.53 / 251.92$ \\
\hline Quercetin & $2.16,1.82^{c}$ & $|27.45 / 348.1|$ \\
\hline Resveratrol & 3.40 & $60.69 / 308.38$ \\
\hline Rosmarinic acid & 3.00 & |44.52/456.2| \\
\hline Salidroside & -0.58 & I I $9.61 / 426.44$ \\
\hline Salvianolic acid B & $\mathrm{pH}$ dependent $\mathrm{d}^{\mathrm{d}}$ & $\mathrm{N} / \mathrm{A}$ \\
\hline Silibinin & 2.63 & $|55| .4 / 6|4.7|$ \\
\hline Tanshinone I & 4.00 & $47.28 / 368.83$ \\
\hline Taxifolin & 1.82 & $127.45 / 367.80$ \\
\hline Thymoquinone & 2.55 & $34.14 / 245.97$ \\
\hline Tyrosol & 1.19 & $40.46 / 219.74$ \\
\hline Ursolic acid & 6.58 & $57.53 / 795.27$ \\
\hline
\end{tabular}

Notes: ${ }^{a} \log P$ and surface area values are obtained from source http://www. chemicalize.org unless specified. 'D Data from Grynkiewicz G, Ślifirski P. Curcumin and curcuminoids in quest for medicinal status. Acta Biochim Pol. 20I2;59(2):20I-2I2. ${ }^{28}$ 'Data from Rothwell JA, Day AJ, Morgan MR. Experimental determination of octanol-water partition coefficients of quercetin and related flavonoids. J Agric Food Chem. 2005;53(I I):4355-4360. ${ }^{29}$ dData from Li J, Liu P, Liu JP, et al. Bioavailability and foam cells permeability enhancement of Salvianolic acid B pellets based on drugphospholipids complex technique. Eur J Pharm Biopharm. 2013;83(I):76-86. ${ }^{30}$ Abbreviation: N/A, not available.

protective autophagy through the ceramide/Akt/mTOR pathway in melanoma B16 cells. ${ }^{39}$ Flavonoid extracts have also been shown to induce autophagy via caspase-dependent activation of signaling pathways by inhibiting sirtuin $1 / \mathrm{p} 53$ mediated mitochondrial and Akt pathways. ${ }^{40}$

Natural compounds have also been observed to inhibit P-glycoprotein (P-gp) in cancer cells. P-gp receptors are responsible for pumping foreign materials out of cells. They are overexpressed in tumor cells, thus reducing the intracellular drug concentrations. Overexpression of P-gp in tumor cells can cause chemotherapeutic drugs to be expelled from targeted tissues, thus reducing the effectiveness of cancer treatments. ${ }^{41}$ Specific types of flavonoids, coumarins, terpenoids, alkaloids, and saponins have been shown to have P-gp-inhibitory properties. Flavonoids and stilbenes have been shown to inhibit ATP-binding cassette transporters, such as P-gp, multidrug resistance-associated protein 1 (MRP1), and breast cancer resistance protein. Common flavonoids that have illustrated these properties are epigallocatechin gallate (EGCG), quercetin, genistein, morin, and kaempferol. EGCG has been shown to downregulate P-gp and breast cancer resistance protein, while quercetin decreases the expression of P-gp in gastric carcinoma cells. ${ }^{42}$ A combination of genistein, quercetin, morin, and kaempferol administered to Panc- 1 cells has also resulted in a decrease in MRP1-mediated transport. ${ }^{43}$

The effect of curcuminoids on the cell cycle of cancer cells has also been studied on lung cancer cell lines A549 and $\mathrm{H} 460 .{ }^{44}$ In both cell lines, the number of sub-G1 cells increased with increased amounts of curcuminoids, and the number of cells at the G0/G1 phase decreased. The addition of curcuminoids did not significantly affect the cells in the $\mathrm{S}$ phase. Only the highest concentration of curcuminoids caused an increase in the G2/M phase cells. The rise in $\mathrm{G} 2 / \mathrm{M}$ phase cells could indicate cell arrest in this phase due to induction of apoptosis. Although both cell lines seem to be arrested in the G2/M phase, this could be cell line dependent. Previous studies have found that the breast cancer cell line MCF-7 is arrested in the G1 phase.

\section{Application to bacterial infection}

Most of the antibiotics we use today are natural products or their derivatives. While larger pharmaceutical companies have paid less effort to developing and screening natural antibiotics, this work has recently been conducted in smaller biotechnology companies. Three recent natural productderived antibiotics that have been approved for use in the USA are: daptomycin, retapamulin, and fidaxomicin. ${ }^{45}$

Other types of natural compounds, such as those discussed in the cancer section, are also being used as antimicrobial agents. Curcumin, cinnamaldehyde, eugenol, and carvacrol are compounds that have been identified as having antimicrobial characteristics. ${ }^{46,47}$ Cinnamaldehyde is isolated from cinnamon; eugenol is derived from cloves, oregano, cinnamon, basil, and bay leaves; and carvacrol is obtained from oregano. These compounds have not yet undergone extensive mechanistic studies. However, some studies have observed that the addition of essential oils from oregano and basil causes a disruption in the cell membrane of bacteria, which leads to cell death. ${ }^{48}$ Other studies have found that cinnamaldehyde and eugenol are involved in the inhibition of cell wall synthesis. ${ }^{49}$ 


\section{Application to other conditions}

Uses of natural compounds for other health conditions are expanding and have received growing attention. Some natural compounds used as anticancer agents also have antiinflammatory characteristics. Compounds such as curcumin, quercetin, eugenol, rosmarinic acid, and kaempferol have anti-inflammatory properties. They suppress proinflammatory pathways, such as transcription factors NF-kappaB and AP-1, and cyclooxygenase-2, an enzyme responsible for inflammation..$^{50,51}$ These compounds have been incorporated into nanoparticles in order to treat cancer, but they could also potentially be used to treat other inflammatory diseases, such as type 2 diabetes.

Many natural products have antioxidant properties that can be used for health benefits. Natural compounds such as quercetin, catechin, ellagic acid, Merremia emarginata extracts, curcumin, luteolin, and taxifolin are just some of the natural products that exhibit antioxidant properties. ${ }^{52-56}$ The mechanism by which these natural compounds obtain their antioxidant properties varies. Quercetin, catechin, curcumin, luteolin, and taxifolin all form phenoxyl radicals on exposure to free radicals in the body. ${ }^{57,58}$ Salvianolic acid B, a strong radicalscavenging compound, also has antioxidant properties. ${ }^{59}$

Natural products have also shown promise in other disease-related applications. Berberine, a quaternary ammonium salt isolated from plants of the Berberis genus, has shown potential in the treatment of hepatosteatosis when incorporated into SLNs. ${ }^{60}$ Berberine SLNs could treat hepatosteatosis by downregulating proteins important for lipogenesis, such as fatty acid synthase, stearoyl-coenzyme A desaturase, and sterol regulatory element-binding protein $1 \mathrm{c}$. Thymoquine, a compound isolated from Nigella sativa, has protective gastrointestinal properties. The mechanism behind these protective properties is free-radical binding. Free radicals are produced in excess after the consumption of ethanol and can lead to mucosal breakup and lesion formation. Thymoquine's free-radical binding activity can protect the tissue and prevent the formation of ethanol-induced gastric ulcers. ${ }^{61}$ Finally, paeonol, which is found in the plant genus Paeonia, has protective action against ultraviolet B (UVB)-induced melanogenesis. Paeonol has been shown to inhibit tyrosinase, which is activated by UVB and produces melanin. ${ }^{62}$

\section{Bioavailability}

Nanoparticles can improve the effectiveness of natural compounds in disease treatment and prevention by increasing their bioavailability. Many of the studied natural compounds, such as curcumin, resveratrol, and EGCG, are highly lipophilic (Table 1). Highly lipophilic compounds are not ideal for drug delivery because they do not dissolve well in the bloodstream. These compounds have a low bioavailability, and therefore large quantities of the compounds must be administered in order to achieve the desired therapeutic effects. The large dose size of these compounds can lead to acute toxicity or low patient compliance. ${ }^{20}$ Just encapsulating these highly lipophilic compounds can improve their water solubility and efficiency. Celia et $\mathrm{a}^{63}$ have found that bergamot essential oil, which has anticancer properties, when encapsulated in liposomes, showed improved solubility of the drug and led to increased cell death in vitro. This was also true for nanoemulsified berberine. The nanoberberine was added to a phosphate buffer and in 45 minutes, $85 \%$ of the compound dissolved, compared to only $60 \%$ of the free berberine in the same time period. ${ }^{64}$ Other classes of natural compounds, such as tannins and terpenoids, are highly hydrophilic. These compounds have low bioavailability because they cannot cross biological membranes. ${ }^{5}$ In both of these cases, incorporating the natural compound into a nanoparticle can improve the bioavailability and lower the dose needed to obtain a therapeutic effect.

Table 2 provides several examples of nanoparticle formulations and adjuvants that increase the bioavailability (drug concentration in plasma) of selected natural compounds. Curcumin, a diarylheptanoid derived from turmeric, has generated immense interest as a lead compound against a variety of health conditions, including cancer, inflammation, microbial infection, angiogenesis, amyloidosis, wound healing, and alleviation of morphine tolerance. ${ }^{70-73}$ However, poor bioavailability is a major limitation to the therapeutic utility of curcumin in clinical trials. ${ }^{74}$ One animal study ${ }^{75}$ found that when $1 \mathrm{~g} / \mathrm{kg}$ of curcumin was orally administered, $75 \%$ of the compound was excreted through the feces. Recently, numerous animal studies have been performed with the goal of improving the bioavailability of this compound. . $^{53,66,67,76-79}$ Takahashi et a ${ }^{53}$ orally administered liposome-encapsulated curcumin (LEC) nanoparticles to Sprague Dawley rats and measured their plasma curcumin levels. The levels in terms of area under the curve (AUC) values were measured for rats administered curcumin and LEC. The AUC values for the LEC were 4.96 times greater than those for curcumin. ${ }^{53}$ Other liposome nanoparticles have also been shown to increase the bioavailability of curcumin. ${ }^{76}$ Similar studies have also been done using SLNs. ${ }^{66,77}$ A pharmacokinetic study conducted with SLNs found that the bioavailability increases dramatically by 39 -fold when $50 \mathrm{mg} / \mathrm{kg}$ of curcumin is administered in the lipid nanoparticle. ${ }^{6}$ Polymer nanoparticles have also 


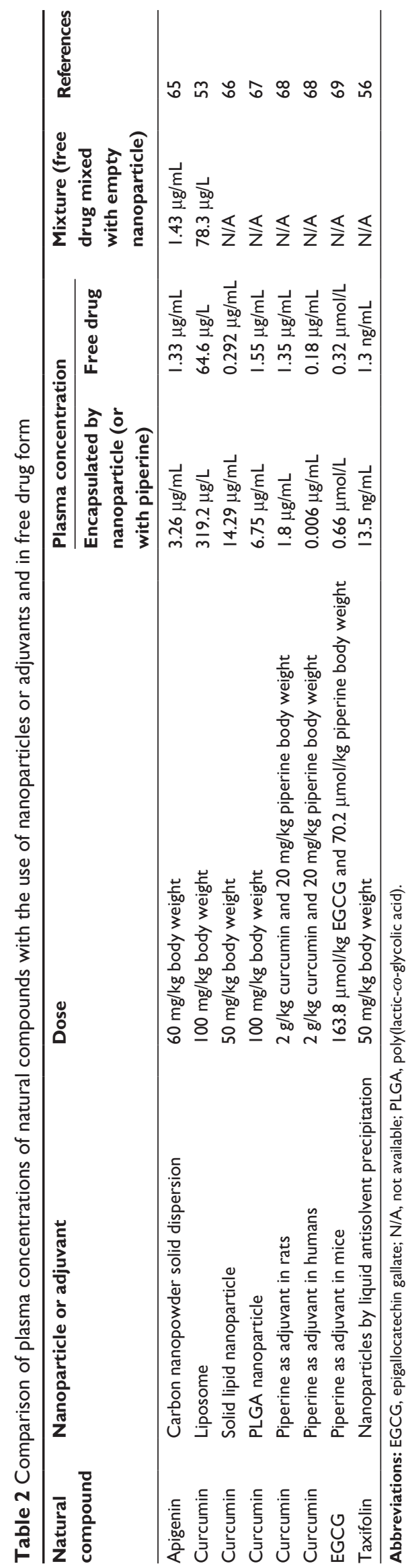

been shown to increase the bioavailability of curcumin. ${ }^{67,78,79}$ In a pharmacokinetic study, ${ }^{67}$ curcumin-loaded PLGA nanoparticles increased the relative oral bioavailability by $563 \%$, compared to free curcumin bioavailability. Other lesscommon types of nanoparticle delivery systems have also been found to increase the bioavailability of curcumin. Wet milling techniques along with crystallization have produced nanosized curcumin particles that have higher bioavailability than the powder counterparts. ${ }^{80,81}$

The mechanism behind PLGA nanoparticles increasing the bioavailability of curcumin has been investigated. ${ }^{67} \mathrm{Xie}$ et $a^{167}$ hypothesized that the increase in bioavailability of curcumin was due to the inhibition of P-gp-mediated efflux. $\mathrm{P}$-gp is abundant in the intestinal membrane. The authors tested this hypothesis by adding verapamil (VRP), a P-gp inhibitor, to curcumin or PLGA-curcumin nanoparticles. After 120 minutes of treatment, the remaining curcumin ratio (RCR) in the jejunum was measured. Significant differences in the RCR were observed for the treatments with plain curcumin versus PLGA-curcumin nanoparticles, either with or without VRP. There was no significant difference in the RCR of curcumin with VRP and the PLGA-curcumin nanoparticles without VRP. These data led the authors to conclude that the PLGA nanoparticles inhibit P-gp, which allows increased drug permeability and bioavailability. In a different study, Shen et $\mathrm{al}^{73}$ compared the attenuation of morphine tolerance in mice induced by curcumin encapsulated in nanoparticles of PLGA and in nanoparticles of PEG- $b$-PLA. The mice that were given the curcuminPLGA nanoparticles orally exhibited significantly greater attenuation of morphine tolerance than those mice given the curcumin-PEG- $b$-PLA nanoparticles, presumably due to greater absorption of the curcumin when formulated with PLGA. These studies demonstrate the significant potential of nanoparticle-mediated drug delivery. Elucidation of the mechanisms of nanoparticle-based natural compound drug delivery will be important in further development of this promising technology.

Nanoparticles have been used to increase the bioavailability of several other natural compounds as well. Apigenin, a plant-derived flavone, has low lipid and water solubility. The solubility was improved by incorporating the compound into a carbon nanopowder solid distribution. Solid dispersion (SD) is a successful technique used to increase the water solubility of certain drugs. Carbon nanopowder is an inert, large-surface-area nanomaterial that reduces the aggregation size of a compound and increases its dispersibility. The oral bioavailability of apigenin carbon SD was investigated in 
Sprague Dawley rats and their plasma concentration was measured. The carbon SD increased the bioavailability of apigenin by $183 \%{ }^{65}$ Thymoquinone, the main bioactive component in Nigella sativa, when encapsulated in a lipid nanocarrier, had a six-fold increase in bioavailability compared to that of free thymoquinone and it showed an increase in gastrointestinal protective properties. ${ }^{61,82}$ Natamycin, an antifungal agent produced by the bacterium Streptomyces natalensis, is commercially available for the treatment of corneal fungal infections. Bhatta et al ${ }^{83}$ used lecithin mucosal adhesive nanoparticles to deliver natamycin and compared it to the commercially available natamycin ophthalmic suspension (USP Natamet). The nanoparticle increased the bioavailability of natamycin by 1.47 -fold and decreased clearance by 7.4-fold. ${ }^{83}$ Icaritin, a flavanol (a glycoside derivative of kaempferol) used to prevent osteoporosis, was incorporated into a nanocrystal. The incorporation caused the AUC value of icaritin to double. ${ }^{84}$ Self-nanoemulsifying quercetin also had an increased bioavailability compared to quercetin alone, with two times higher AUC values. ${ }^{85}$ Taxifolin, a flavanol plant derivative, also had improved bioavailability when incorporated into a nanoparticle. In this experiment, nanoparticles of pure taxifolin were formed by liquid antisolvent precipitation in which the size of these nanoparticles could be controlled by the precipitation conditions. The oral bioavailability of the nanoparticles was seven times that of normal taxifolin. ${ }^{56}$ Polymeric nanoparticles have been utilized to increase the bioavailability of luteolin, EGCG, tea polyphenols, and silibinin, using polymers such as PEG, PVA, and PLA. ${ }^{86-89}$ As mentioned earlier, EGCG has been shown to inhibit P-gp, which is abundant in the intestinal lining. Work by Dube et $\mathrm{al}^{12}$ has shown that EGCG encapsulated by chitosan nanoparticles significantly increased intestinal absorption compared to EGCG alone. ${ }^{12}$ This leads to an increased bioavailability of the compound.

As discussed above, use of nanoparticles is one way to significantly increase the bioavailability of natural compounds. The improvement in their pharmacokinetic properties leads to a better therapeutic effect, without highdose-induced acute toxicity. Nanoparticles, however, are not the only resource to increase the bioavailability of natural compounds. Researchers have found that the addition of adjuvants to curcumin can also improve its bioavailability. Piperine has been one of the most promising adjuvants. A few mechanisms may contribute to piperine's ability to increase curcumin's bioavailability. One of the possible mechanisms is inhibiting the glucuronidation of curcumin. ${ }^{7}$ Glucuronidation-based small-molecule metabolism involves the addition of a glucuronic acid group to curcumin, which reduces curcumin's activity. Another contributing mechanism is that piperine has been shown to inhibit P-gp and cytochrome P450 (CYP) 3A4. ${ }^{90}$ As discussed above, $\mathrm{P}$-gp is responsible for pumping materials out of the intestinal lining and thus reduces bioavailability. This receptor is an ATP-binding cassette transporter, which utilizes ATP hydrolysis to position the drug and excrete it from the membrane. P-gp is not structurally specific, although it usually binds to hydrophobic substrates. ${ }^{91} \mathrm{CYP} 3 \mathrm{~A} 4$ is an enzyme in the liver responsible for oxidizing small molecules. Oxidation, like glucuronidation, can decrease the activity of small molecules such as curcumin. Because of these mechanisms, piperine is a good adjuvant to increase the bioavailability of curcumin. The combination of piperine and curcumin in rats increased the bioavailability by $154 \%$, whereas the combination in human volunteers increased the bioavailability by $2,000 \%{ }^{68}$ Adjuvants alone do not have some of the other beneficial properties of nanoparticles, but piperine could be added to the natural compounds/nanoparticles to further increase their bioavailability.

Other types of nanomaterials can also be used to provide better bioavailability to natural compounds. Studies involving unique types of nanodelivery devices and their use with natural compounds have been conducted, but pharmacokinetic studies have not yet been performed. It is important to note that after the addition of these nanomaterials, the therapeutic effects of the compounds increase. For example, a silk fibroin nanoparticle was developed to treat breast cancer. The nanoparticle contained curcumin and was composed of a mixture of silk and chitosan. Although the pharmacokinetic properties were not studied, the uptake of curcumin by the breast cancer cell line (MCF-7) was significantly increased after the addition of the silk fibroin nanoparticle. ${ }^{92}$ In another study, quercetin-loaded $\beta$-cyclodextrin dodecylcarbonate nanoparticles were used on SH-SY5Y neuronal cells. ${ }^{93}$ The quercetin nanoparticles caused a decrease in inflammatory mediators, such as cluster of differentiation 36 (CD36), $\beta 1$-integrin, interleukin-8, monocyte chemoattractant protein-1 and matrix metalloproteinase-9. Other studies have also found that incorporating natural products into nanoparticles can improve the health benefits of the drug. Traditional Chinese medicines isolated from plants and made into nanoparticles improved the compounds' hepatoprotective effects, and camptothecin encapsulated in liposomes increased the drug's ability to kill melanoma cells. ${ }^{94,95}$ These examples illustrate the benefits nanoparticles can have on natural compound delivery. Future studies should 
be performed to determine the factors causing the increase in delivery efficiency and bioavailability.

Another approach for increasing bioavailability of poorly soluble natural compounds and drugs is to form amorphous solid dispersions (ASDs) of the therapeutic compound with a polymer. This has been demonstrated with micron-scale and larger particles, but not so far with nanoparticles. ${ }^{96}$ Most drugs and natural compounds tend to crystallize, which is a barrier to dissolution at physiological conditions. Those natural compounds that are also highly hydrophobic exhibit especially poor bioavailability due to the combination of hydrophobicity and crystallinity. ASDs are solid solutions of the therapeutic agent in an amorphous polymer carrier in which attractive interactions prevent crystallization. It is important to choose the polymer for biocompatibility and controlled release of the drug under physiological conditions and for good storage stability. In particular, polysaccharides have recently been demonstrated to form ASDs that significantly enhance the solubility of natural compounds including ellagic acid, quercetin, curcumin, naringenin, and resveratrol. ${ }^{97-99}$ These studies suggest that ASDs in nanoparticle form could potentially be very useful in improving bioavailability through improved solubility and transport across physiological barriers.

The route of delivery greatly affects a drug's bioavailability. The definition of bioavailability is the proportion of a drug that enters the circulation and is able to have an active effect. For the majority of this section, the route of delivery has been oral. Oral delivery is beneficial because it has high patient compliance. Another route that is appealing is topical administration. One of the main issues with this route is extremely low bioavailability. Nonsteroidal antiinflammatory drugs are some of the most common topical administered drugs, and their bioavailability is generally less than $5 \%-15 \%$. However, nanotechnology may be able to enhance the route of topical administration. ${ }^{100}$ Lycopene, an active compound in tomatoes, has also been incorporated using nanotechnology for topical administration. Lycopene has been shown to have anti-inflammatory properties without the side effects of typically used steroids. Lycopene was incorporated into either a "transfersome" or an endosome, which are artificial vesicles similar to a liposome. The effectiveness of this drug was compared to that of betamethasone, an anti-inflammatory steroid. The lycopene in the "transfersome" and endosome reduced the swelling by $97 \%$ and $87 \%$, respectively, which was comparable to that of the betamethasone. ${ }^{101}$ Another study developed a topical salidroside and paeonol nanosphere hydrogel to protect against UV-induced melanoma. ${ }^{62}$ These results suggested that the use of natural compounds with a nanoparticle could potentially be used in topical delivery to replace current creams.

A similar route to topical delivery is transdermal administration. This route also requires the drug to have the ability to penetrate the skin. In one study, ${ }^{102}$ the ethanolic extract of apple peel, which has been shown to have photoprotective properties, encapsulated by PLGA nanoparticles underwent transdermal administration. The nanoparticle also included oleic acid, a permeation enhancer, to further increase the particles' bioavailability. The nanoformations released $90 \%$ of the drug, whereas only $25 \%$ of the drug was released in the cells exposed to the free drug. ${ }^{102}$

Even though nanoparticles have great potential to considerably improve the bioavailability of natural compounds and there has recently been significant progress in the development of such formulation, very few nanoparticle/natural compound drugs are currently being tested in clinical trials. More work needs to be performed to optimize these drug delivery systems and to better understand the mechanisms underlying the enhanced nanoparticle delivery.

\section{Targeting}

A second major benefit in utilizing nanoparticles in drug delivery of natural compounds is their ability to target specific tissues or organs. Targeting is beneficial for a number of reasons. First, targeting can improve drug bioavailability by increasing the fraction of the drug that reaches the tissue of interest. Second, targeted drug delivery can reduce toxic side effects of the drug because it is mainly being released in a localized area of the body. Due to the different types of nanoparticles, a number of targeting approaches are possible, which can fall under two general categories. The first is active targeting, where a targeting ligand is attached to the surface of a nanoparticle. The second type is passive targeting, in which the nanoparticle reaches the targeted area without specific chemical interaction but, instead, relies upon physical transport of the particles due to their intrinsic properties, such as size, shape, and surface charge. ${ }^{103}$ These targeting methods and their advantages are summarized in Table 3.

Active targeting is usually accomplished by functionalizing the nanoparticles with a protein, peptide, antibody, or small molecule. This functionalization allows the particle to be localized and internalized by specific tissues or organs. The use of monoclonal antibodies conjugated onto nanoparticles has shown promise in targeting the bloodbrain barrier (BBB). However, this has not been used in conjunction with natural compounds. ${ }^{112}$ Conjugation of 


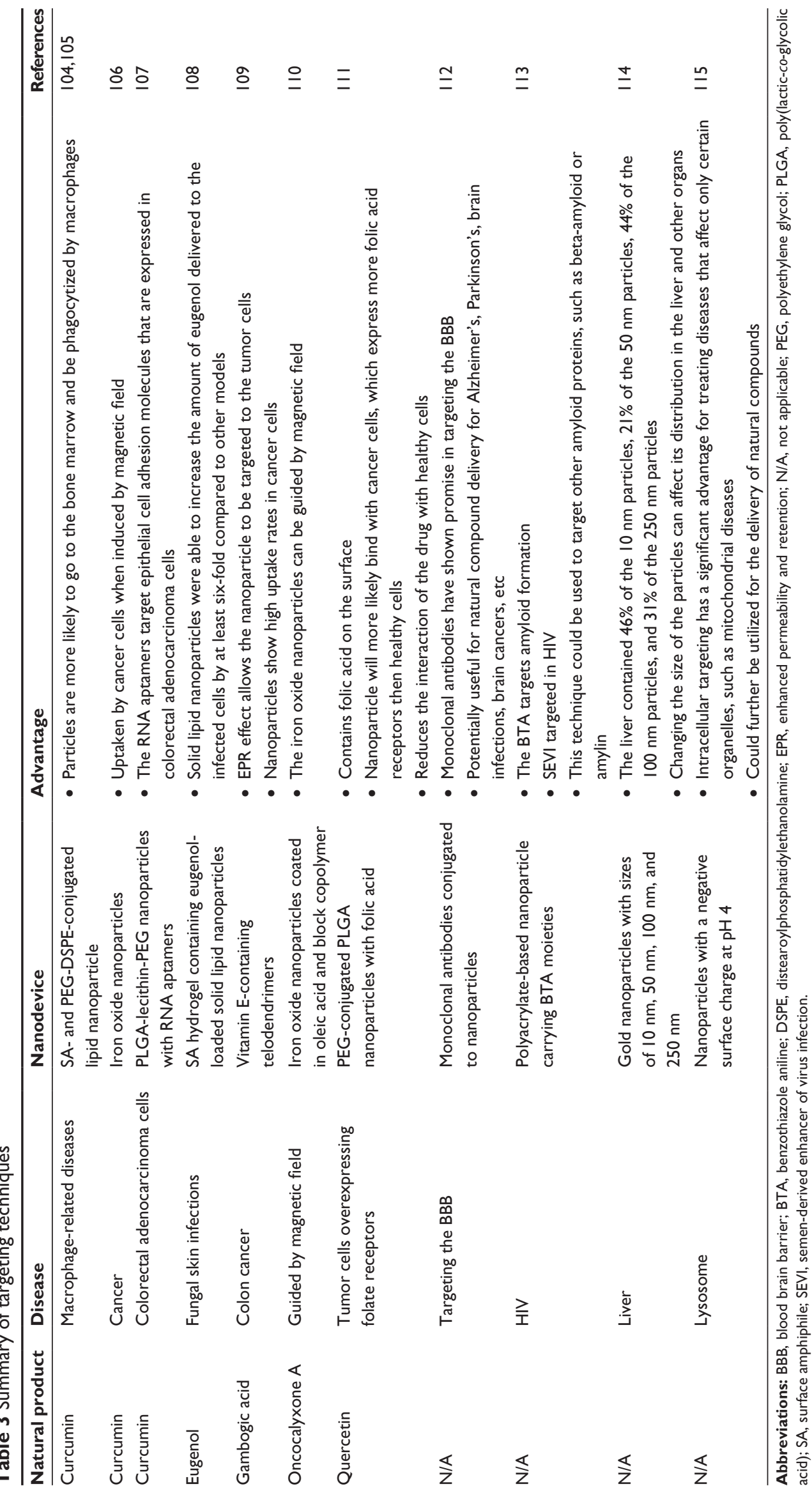


nanoparticles with folic acid (FA) has shown promise in the treatment of cancer cells. Because many types of cancers overexpress FA receptors on the cell surface, attaching FA to a nanoparticle will enable it to target cancer cells. This technique was used in the case of quercetin encapsulated in PLGA nanoparticles that were stabilized by PEG, which increases the nanoparticle biocompatibility and the circulation lifetime. The nanoparticles were then conjugated with FA. HeLa cells were used as a FA-expressing cancer cell line. Non-PEGylated non-FA-targeted nanoparticles, PEGylated non-FA-targeted nanoparticles, and PEGylated FA-targeted nanoparticles were all tested on the HeLa cell line. The cell viability was lowest with the PEGylated FAtargeted nanoparticles (56.63\% cell viability) compared to the controls: quercetin alone $(84.36 \%)$, non-PEGylated non-FA targeted nanoparticles $(83.22 \%)$, and PEGylated non-FA targeted nanoparticles (81.27\%). Cellular uptake of the nanoparticles was also measured, and the PEGylated FA-targeted nanoparticles had a significantly higher cellular uptake than the other nanoparticle models. ${ }^{111}$ Sou et al ${ }^{104,105}$ developed another targeting technique, using curcumin lipid nanoparticles to target bone marrow macrophages. Surface modification of the lipid nanovesicles with an anionic amphiphile, L-glutamic acid, $N$-(3-carboxy-1-oxopropyl)-, 1,5-dihexadecyl ester, resulted in significant targeting of vesicles to the bone marrow. Further incorporation of PEG-lipid passively enhanced the distribution of succinic acid vesicles into the bone marrow. ${ }^{104,105}$ Curcumin has also been incorporated into PLGA-lecithin-PEG nanoparticles with covalently attached RNA aptamers against epithelial cell adhesion molecules. This allows the nanoparticle to target colorectal adenocarcinoma cells. These nanoparticles successfully targeted colorectal cancer cells and enhanced cellular uptake of curcumin. ${ }^{107}$

Functionalizing nanoparticles with small molecules for targeted delivery of natural compounds is a relatively new development. Thus, more research work is needed to apply previously developed targeting techniques to the field of natural compounds. For example, benzothiazole aniline (BTA) is a known amyloid-binding compound and has been shown to prevent beta-amyloid protein aggregations. ${ }^{116}$ It also inhibits semen-derived enhancer of virus infection, which increases the infectiousness of HIV. Polyacrylate-based nanoparticles functionalized with BTA were used to impede semen-derived enhancer of virus infection mediation in HIV-infected cells. ${ }^{113}$ Certain natural compounds, such as curcumin, have demonstrated anti-Alzheimer properties. ${ }^{117}$ The BTA-based nanoparticle described above could potentially be modified to improve the delivery of these natural compounds for betterquality treatment of Alzheimer's disease.

Targeting can also be achieved using external forces. The use of magnetic fields to direct a delivery system has gained some attention. Iron oxide nanoparticles were prepared and loaded with curcumin and incubated with MDAMB-231 cells, a breast cancer cell line, in the presence of an external magnetic field generated by a neodymium permanent magnet. The magnetic field significantly increased the uptake and targeting of the cancer cells. ${ }^{106}$ A similar study ${ }^{110}$ was done with oncocalyxone $\mathrm{A}$, an extract from the Brazilian plant Auxemma oncocalyx with antitumor activity. Iron oxide nanoparticles coated in oleic acid and oncocalyxone A were incorporated into the hydrophobic cores of block copolymer micelles. Incorporated iron oxide allows the nanoparticles to be directed by a magnetic field to the tumor. ${ }^{110}$

Passive targeting is often an effective and less-expensive option that is most often used in tumor treatment. Many tumors exhibit the enhanced permeability and retention (EPR) effect caused by leaky vasculature in the tumor. ${ }^{11}$ This results in a buildup of nanoparticles preferentially in the tumor compared to healthy tissue. An example is the delivery of encapsulated gambogic acid and vitamin E-containing telodendrimers for colon cancer treatment. ${ }^{109}$ Gambogic acid has been shown to inhibit the growth of several types of cancer lines, including colon cancer. Dendrimers are hierarchically branched molecules on the nanoscale (Figure 1A). The telodendrimers were made of a PEG-containing, dendritic oligomer of cholic acid and vitamin E. These telodendrimers self-assembled to form spherical nanoparticles similar to micelles. After the telodendrimer was optimized, it was labeled with a fluorescent lipophilic cationic indocarbocyanine dye and injected into mice. The telodendrimers showed a high uptake in the tumor, whereas the dye alone had a higher uptake in the liver, lung, and spleen, but a lower uptake in the tumor.

The reticuloendothelial system can also be passively targeted. For example, the biodistribution of gold nanoparticles with sizes ranging from $10 \mathrm{~nm}$ to $250 \mathrm{~nm}$ was studied in rat models. Gold uptake in the liver, spleen, lung, kidney, testis, thymus, heart, and brain was quantitated using inductively coupled plasma mass spectrometry. The liver was found to have the highest percentages of the injected dose, containing $46 \%$ of the $10 \mathrm{~nm}$ particles, $21 \%$ of the $50 \mathrm{~nm}$ particles, $44 \%$ of the $100 \mathrm{~nm}$ particles, and $31 \%$ of the $250 \mathrm{~nm}$ particles. ${ }^{114}$ This experiment showed the strength of passive targeting. Up to $46 \%$ of the nanoparticles can be targeted to the liver 
without the addition of any targeting molecules. Although this type of experiment has not been performed using natural compounds, it could be used as a potential targeting mechanism in the future.

Another strategy for targeting is to manipulate the lipophilicity of the nanoparticles. This technique is especially important in targeting the brain. The BBB favors crossing over of lipophilic molecules. By adjusting this property, control is placed on where the nanoparticles go, and therefore, this technique can be used to target the distribution toward specific locations. ${ }^{5}$ Stearic acid hydrogel containing eugenol-loaded SLN was targeted to the epidermis to treat fungal skin infections. These nanoparticles were compared against a eugenol-hydroxypropyl- $\beta$-cyclodextrin complex in hydrogel, a less-lipophilic nanoparticle, and an almond oil solution of eugenol. The SLN hydrogel showed an accumulation of $62.65 \%$, compared to the other models, with values of $9.77 \%$ and $3.45 \%$, respectively. This is another example of varying the characteristics of the nanoparticles in order to better target the area of interest. ${ }^{108}$

Nanoparticles can also be targeted to certain organelles within the cell by manipulating the surface charge. In one study, nanoparticles that were negatively charged at $\mathrm{pH} 4$ ( $\mathrm{pH}$ of the lysosome) remained in the lysosome, while nanoparticles that were positively charged were released into the cytoplasm. ${ }^{115}$ Furthermore, nanoparticles with surface modification to carry a positive charge may allow targeting to the mitochondria. ${ }^{118}$

\section{Controlled release}

A third benefit of using nanoparticles to deliver natural compounds is that the release of the drug can be controlled. The amount and rate at which a drug is released from a nanoformulation depends on a multitude of factors, including particle type and size, amount of drug encapsulated, natural compound used, and the microenvironment. ${ }^{24}$ Recent examples of natural product-based nanoparticles and their properties for controlled release are summarized in Table 4.

The type of nanoparticle used prominently affects the drug release profile. If a polymer nanoparticle is used, the types of polymers can be further adjusted to affect the release profile. Polymers that are biocompatible, such as PEG, increase the time the nanoparticles stay in the body without being excreted or detected by the immune system. Therefore, PEG is often used to increase the release time in a delivery system. In one study, the release of curcumin encapsulated in copolymers of $N$-isopropylacrylamide and $N$-vinyl-2-pyrrolidone with the addition of poly(ethyleneglycol)monoacrylate (PEG-A) was measured. This copolymer particle allowed for a sustained release of the drug. After 24 hours, only $40 \%$ of the drug had been released. ${ }^{121}$ The release patterns of quercetin encapsulated in PLA nanoparticles were studied over a period of 96 hours. Within the first half hour, 40\%-45\% of the quercetin was released. This quick burst was attributed to the quercetin at the surface of the particle diffusing into the surroundings. Over the next 96 hours, the release was slower and reached a maximum of $87.6 \%$. This slower release was attributed to the diffusion of the quercetin from deeper within the nanoparticle. ${ }^{128}$

The release rate of pentacyclic triterpenediol, a natural product with anticancer properties isolated from Boswellia serrata, encapsulated in an SLN was studied by Bhushan et al. ${ }^{127}$ The release profile was similar to that of many polymer nanoparticles, with an initial burst followed by a slow, controlled-release pattern. ${ }^{127}$ Another type of nanoparticle has three phases in the release profile. Mesoporous silica nanoparticles, which are silica nanoparticles with holes along the surface to increase surface area and drug loading capacity, present a unique way to increase the release time of a drug. This type of nanoparticle can also be modified for the specific drug and release profile desired. Mesoporous silica nanoparticles, covalently bonded to rhodamine $\mathrm{B}$, were studied. ${ }^{130}$ The particles had a large surface area and pore volume and a positively charged surface (due to the rhodamine B). This was ideal for loading salvianolic acid $\mathrm{B}$, a negatively charged natural product. Mesoporous nanoparticles with and without rhodamine B were compared. Three phases of release were observed over a 144-hour period. The first phase was an initial burst, in which nanoparticles without rhodamine B released more drugs. The second phase included a slower drug release, in which both nanoparticles released around the same amount of drug. In the third phase, the nanoparticles without rhodamine B stopped releasing significant amounts of salvianolic B, while the nanoparticles with rhodamine $\mathrm{B}$ continued to release the drug. ${ }^{130}$

The hydrophilic/lipophilic properties of a polymer can also be manipulated to adjust the drug release profile. Ellagic acid, a naturally occurring phenol, was encapsulated in PLGA nanoparticles. The PLGA polymer was combined with didodecyldimethylammonium bromide (DMAB), PVA, or polyvinyl alcohol with chitosan. The release rates for these three nanoparticles were evaluated over 25 days. The PVA nanoparticles showed the fastest release; $50 \%$ of the drug was released over the first 6 days. Polyvinyl alcohol 
Table 4 Natural product-based nanoparticles for controlled release

\begin{tabular}{|c|c|c|c|}
\hline Natural product & Nanodevice & Properties & References \\
\hline Cinnamic acid & $\begin{array}{l}\text { Lecithin-lipid } \\
\text { nanoliposomes with PL- } \\
\text { DHA, salmon, or soya } \\
\text { lecithin phospholipids }\end{array}$ & $\begin{array}{l}\text { - Entrapment efficiency may depend on liposome size } \\
\text { - Salmon: } 91.4 \% \\
\text { ○L-DHA: } 76.4 \% \\
\text { ○ Soya lecithin: } 68.6 \%\end{array}$ & 119 \\
\hline $\begin{array}{l}\text { Coumarin- } 6 \text { ginsenoside, } \\
\text { salvianolic acid B }\end{array}$ & PLGA nanoparticles & $\begin{array}{l}\text { - Natural product-PLGA interactions may significantly affect the entrapment } \\
\text { efficiency (percentage) } \\
\text { - Coumarin-6: } 51.6 \% \\
\text { - Ginsenoside: } 93.56 \% \\
\text { - Salvianolic acid B: } 92.88 \%\end{array}$ & 120 \\
\hline Curcumin & $\begin{array}{l}\text { NIPAM/NVP/PEG } \\
\text { polymer nanoparticles }\end{array}$ & - PEG extends release time: only $40 \%$ of the drug released after 24 hours & 121 \\
\hline Curcumin & PLGA nanoparticles & $\begin{array}{l}\text { - Tested in gastric environment }(\mathrm{pH} 2) \text { and in intestinal environment }(\mathrm{pH} 7) \\
\circ \text { Intestinal: } 77 \% \text { of the drug released in } 7 \text { days } \\
\circ \text { Gastric: } 48 \% \text { released in } 7 \text { days }\end{array}$ & 67 \\
\hline Curcumin & $\begin{array}{l}\text { Eudragit SI00 polymer } \\
\text { nanoparticles }\end{array}$ & $\begin{array}{l}\text { - Polymer dissolves at pH } 7 \\
\text { - Targets intestines and treats inflammatory bowel disease }\end{array}$ & 122 \\
\hline Curcumin & $\begin{array}{l}\text { PLA and PVA } \\
\text { microspheres with } \\
\mathrm{Fe}_{3} \mathrm{O}_{4} \text { paramagnetic } \\
\text { nanoparticles }\end{array}$ & $\begin{array}{l}\text { - Without } \mathrm{Fe}_{3} \mathrm{O}_{4}: 90.35 \% \text { of the drug released after } 72 \text { hours } \\
\text { - With } \mathrm{Fe}_{3} \mathrm{O}_{4}: 49 \% \text { released after } 72 \text { hours } \\
\text { - Curcumin interacts with large-surface-area nanoparticles and release } \\
\text { is slowed down }\end{array}$ & 123 \\
\hline Curcuminoids & SLN in cream & $\begin{array}{l}\text { - Topical delivery } \\
\text { - SLNs with curcuminoids: } 70 \% \text { of the drug released after } 8 \text { hours } \\
\text { - Free curcuminoids: } 90 \% \text { released after } 8 \text { hours }\end{array}$ & 124 \\
\hline EGCG & $\begin{array}{l}\text { Polysaccharide } \\
\text { nanoparticles }\end{array}$ & $\begin{array}{l}\text { - Fast release time: } 46 \% \text { released in the first } 10 \text { minutes, } 100 \% \text { released } \\
\text { in } 3 \text { hours }\end{array}$ & 125 \\
\hline Ellagic acid & $\begin{array}{l}\text { PLGA nanoparticles } \\
\text { with DMAB, PVA, or } \\
\text { PVA-CS }\end{array}$ & $\begin{array}{l}\text { Release rate affected by hydrophobicity of polymer (PVA is least } \\
\text { hydrophobic) } \\
\text { OPVA: } 50 \% \text { of the drug released in the first } 6 \text { days } \\
\text { PVA-CS: } 38 \% \text { released in the first } 6 \text { days } \\
\text { DMAB: } 24 \% \text { released in the first } 6 \text { days }\end{array}$ & 52 \\
\hline $\begin{array}{l}\text { Eugenol and trans- } \\
\text { cinnamaldehyde }\end{array}$ & PLGA nanoparticles & $\begin{array}{l}\text { - Trans-cinnamaldehyde: } 87 \% \text { of the drug released in } 72 \text { hours } \\
\text { - Eugenol: } 64 \% \text { released in } 72 \text { hours }\end{array}$ & 126 \\
\hline $\begin{array}{l}\text { Pentacyclic } \\
\text { triterpenediol }\end{array}$ & SLN & - Two phases: initial quick burst followed by slow release & 127 \\
\hline Quercetin & PLA nanoparticles & $\begin{array}{l}\text { - Two phases: } \\
\text { - Quick burst: } 40 \%-45 \% \text { released in } 30 \text { minutes } \\
\text { - Slow release: } 87.6 \% \text { released in the next } 96 \text { hours }\end{array}$ & 128 \\
\hline Quercetin & $\begin{array}{l}\text { Lecithin-based cationic } \\
\text { nanocarrier }\end{array}$ & $\begin{array}{l}\text { - Interactions between nanoparticle and natural product lead to a higher } \\
\text { entrapment efficiency } \\
\text { - Entrapment efficiency is as high as } 91.3 \%\end{array}$ & 129 \\
\hline Salvianolic acid B & $\begin{array}{l}\text { Mesoporous silica } \\
\text { nanoparticle with and } \\
\text { without RhB }\end{array}$ & $\begin{array}{l}\text { - RhB carries a positive charge that attracts negatively charged salvianolic acid B } \\
\text { - Three phases: } \\
\text { - Quick burst (nanoparticles without } \mathrm{RhB}>\text { nanoparticles with } \mathrm{RhB} \text { ) } \\
\text { - Slow release (nanoparticles without } \mathrm{RhB}=\text { nanoparticles with } \mathrm{RhB} \text { ) } \\
\text { - Slower release (nanoparticles without } \mathrm{RhB}<\text { nanoparticles with } \mathrm{RhB} \text { ) }\end{array}$ & 130 \\
\hline
\end{tabular}

Abbreviations: CS, chitosan; DMAB, didodecyldimethylammonium bromide; EGCG, epigallocatechin gallate; NIPAM, N-isopropylacrylamide; NVP, N-vinyl-2-pyrrolidone; PEG, polyethylene glycol; PLA, poly-L-lactic acid; PL-DHA, phospholipids containing docosahexaenoic acid; PLGA, poly(lactic-co-glycolic acid); PVA, polyvinyl alcohol; RhB, rhodamine B; SLN, solid lipid nanoparticles.

with chitosan was the second fastest, with $38 \%$ of the drug released after 6 days and DMAB was the slowest, with 24\% being released in 6 days. The release rate was thought to be affected by the hydrophilic nature of each of the polymers. PVA has hydrophilic groups in the polymer, which allow water molecules to penetrate and increase the release of ellagic acid..$^{52}$ Other polymer types have been tested and have had drug release analyses performed, including PLGA and PCL, to deliver camptothecin. ${ }^{131}$ PLGA nanoparticles were used to deliver phytochemical tropical fruit-derived 
natural products, ${ }^{132}$ and PLA nanoparticles were used to deliver quercetin. ${ }^{128}$

The microenvironment is another factor that can be manipulated in order to control the release profile of a drug. Xie et $a^{16}{ }^{67}$ tested the release profile of curcumin-loaded PLGA nanoparticles in different microenvironments in vitro. An artificial gastric environment was created using phosphatebuffered saline at $\mathrm{pH} 2$ (adjusted with $\mathrm{HCl}$ ), and an artificial intestinal environment was created using phosphate-buffered saline at $\mathrm{pH}$ 7.4. The PLGA nanoparticles were agitated in suspension in the two environments over a period of 7 days, and the amount of curcumin released was measured by highperformance liquid chromatography. More curcumin was released in the artificial intestinal environment than in the gastric environment throughout the entire period. At the end of the 7 days, $77 \%$ of curcumin was released in the intestinal environment, whereas only $48 \%$ was released in the gastric environment. ${ }^{67}$ The environment that a drug delivery system will encounter in its journey to the target site is an important factor to consider when designing a nanoparticle. As described above, the release profile of a drug is dependent on a number of factors, one of which is $\mathrm{pH}$. For example, nanoparticles that are used to treat inflammatory bowel disease can be designed to have maximum release in the intestinal environment to increase the amount of drug that reaches the target site. Gugulothu et al ${ }^{122}$ utilized this idea when the team designed a $\mathrm{pH}$-sensitive polymer nanoparticle. This nanoparticle dissolves at $\mathrm{pH} 7$, the $\mathrm{pH}$ of the intestinal tract. If orally administered, the majority of this polymer (Eudragit S100) will stay intact until it reaches the intestines, where it will deliver the drug. Curcumin and celecoxib, an anti-inflammatory drug, were both encapsulated in the $\mathrm{pH}$ sensitive polymer in order to better treat inflammatory bowel diseases such as ulcerative colitis and Crohn's disease. ${ }^{122}$

Controlled release can also be achieved by manipulating the environment within the particle. The release of curcumin from a polymer microsphere was controlled with the addition of $\mathrm{Fe}_{3} \mathrm{O}_{4}$ (magnetite) nanoparticles. The curcumin and the magnetite nanoparticles were encapsulated in PLA and PVA/PEG polymers and the release rate of the curcumin was measured and compared to that from the microsphere without the magnetite nanoparticles. The microspheres that did not contain magnetite released $90 \%$ of the curcumin after 72 hours. The magnetite-containing microspheres, however, only released $49 \%$ of the curcumin after 72 hours. Those microspheres, like the normal microspheres, exhibited an initial burst of curcumin, but this was followed by a slower release rate, which was thought to be due to the interaction of the curcumin and the magnetite nanoparticles that have a large surface area with which curcumin could bind. ${ }^{123}$

Polymer nanoparticles are not the only type of nanoparticle in which release kinetics has been studied. In one study, a cream containing SLNs carrying curcuminoids was compared to free curcuminoids. The SLN slowed the release kinetics. After 12 hours, the SLN had released $70 \%$ of the curcuminoids, whereas $90 \%$ of the free curcuminoids were released within 8 hours. ${ }^{124}$

The type of natural compound contained in the nanoparticle also affects the release kinetics. In one study, ${ }^{126}$ eugenol and trans-cinnamaldehyde were encapsulated in PLGA nanoparticles and the release profiles were measured over 72 hours. The structure and size of the nanoparticles were analogous, but the release profiles were quite different. Both nanoparticles had two phases of release, an initial burst and a slow release. At the end of the 72 hours, $87 \%$ of the trans-cinnamaldehyde had been released, whereas only $64 \%$ of the eugenol was released. The release constants were also measured. For the burst phase, the rate constants were $1.76 \times 10^{-4} \mathrm{~s}^{-1}$ for cinnamaldehyde and $4.10 \times 10^{-4} \mathrm{~s}^{-1}$ for eugenol. During the second, slow release phase, the constants were $2.75 \times 10^{-6} \mathrm{~s}^{-1}$ and $1.65 \times 10^{-6} \mathrm{~s}^{-1}$, respectively. These data show that eugenol is released at a much faster rate than cinnamaldehyde during the initial burst, but at a slower rate during the second phase. This difference in the release of the compounds was believed to be due to the interactions of cinnamaldehyde and eugenol with the PLGA. ${ }^{126}$

Drug release from nanoparticles can be triggered using ultrasound, light, and other physical and chemical environmental changes. ${ }^{133,134}$ Recently, a new light-sensitive polymer based on the quinone-methide system was developed, which degrades when exposed to irradiation at $350 \mathrm{~nm}$ and $750 \mathrm{~nm} .{ }^{133}$ Nanoparticles made with this polymer released an encapsulated drug (in this case, the Nile Red dye) when exposed to the specific light wavelength(s). This technology combines targeting and controlled release to make a delivery system that could greatly reduce the drugs' interaction with other tissues in the body.

An important aspect that affects the release of a drug is the entrapment efficiency or encapsulation efficiency (EE) defined as $\mathrm{EE}=$ (total concentration - supernatant concentration)/ total concentration. The entrapment efficiency is important because a nanoparticle with a low efficiency means wasted compound and higher costs. Larger entrapment efficiency also means more drug release in vivo. It is therefore important 
to have a nanoparticle with the highest entrapment efficiency. A study by Bouarab et al $^{119}$ investigated the entrapment efficiency of cinnamic acid encapsulated within lecithin-lipid nanoliposomes. Three different phospholipids were studied, a phospholipid derivative of docosahexaenoic acid, as well as salmon and soya lecithin. Salmon lecithin showed the highest entrapment efficiency, estimated to be $\sim 91.40 \% \pm 1.39 \%$, then came phospholipids containing docosahexaenoic acid, with $76.4 \% \pm 0.98 \%$, and soya lecithin with $68.63 \% \pm 1.21 \%$. The entrapment efficiency could be correlated to the liposome size, whereby the larger liposomes have higher entrapment efficiency. Another property that affects the EE of a natural compound in a nanoparticle is the interaction between the particle and the compound. Quercetin was encapsulated in a lecithin-based cationic nanocarrier (LeciPlex) and had a high encapsulation rate of $91.3 \%$. The authors correlated this high EE to the strong interactions between quercetin and the LeciPlex. ${ }^{129}$ The natural compound used also affects the encapsulation efficiency. Cai et al ${ }^{120}$ encapsulated different natural products within PLGA nanoparticles and found that each compound had a different encapsulation efficiency. Coumarin-6, a phenylpropanoid, had the lowest EE, 51.6\%, whereas ginsenoside and salvianolic acid B had the highest EE, 93.56\% and 92.88\%, respectively. The highest encapsulation efficiencies may be due to stronger interactions between the compound and the PLGA. ${ }^{120}$

Controlling the release of a drug from the nanoparticle is a powerful tool. Drug release kinetics can affect how much of the drug arrives at its targeted location. Optimizing the nanoparticle based on the target location, properties of the natural compound, and preferred nanoparticle type may take a significant amount of time, but the benefits will be significant.

\section{Issues}

One of the major problems with nanoparticle delivery systems is their potential toxicity. This is a major concern with nanoparticles, partly because they can cross biological membranes, such as cellular membranes and, in some special cases, the BBB. ${ }^{12,135}$ Cells with phagocytosis ability can take up nanoparticles between $100 \mathrm{~nm}$ and 1,000 nm. Nanoparticles $<100 \mathrm{~nm}$, however, can be taken up by cells via endocytosis and could potentially cause systemic toxicity and harm if their biodistribution is not controlled and if they contain toxic polymers or drugs or if they form toxic metabolites. Nanoparticles that can be taken up by cells need to undergo extensive screening, to ensure no harm will come to healthy cells. ${ }^{136}$ Although numerous studies have claimed that nanoparticles composed of biocompatible polymers (PLGA, PEG, etc), phospholipids (liposomes and micelles), and other materials are safe and show no toxicity to healthy cells, additional studies are clearly needed. ${ }^{137}$ Many of the studies discussed in this review have not completed a toxicity study on healthy cell lines.

Another issue that arises when using nanoparticles as drug delivery systems is that the nanoparticle will undergo changes in the body. It is known that the surface of nanoparticles change as the particles move through different membranes, tissues, and organs in the body. As the nanoparticle moves, proteins become attached to the surface and change the shapes and surface charges of the particles. Interactions with surfaces may also strip the nanoparticles of ligands that were originally present on its surface. The nanoparticle that arrives at the targeted location may thus not be the same as the nanoparticle originally administered. ${ }^{138}$ This must be taken into account, because the changes could affect the bioavailability, targeting, and release kinetics of the drug.

Targeted nanoparticle delivery of natural compounds is a significant benefit. Although most natural compounds show low toxicity, high-dose-induced side effects are a major reason for low patient compliance. Targeted delivery can reduce side effects and limit potential toxicity. However, targeting has challenging issues that must be overcome. The ultimate goal for a targeted drug delivery system is to create a specific drug-carrier combination that enhances the delivery or uptake in a specific area of the body. This will result in a higher therapeutic effect and lower side effects. In order to achieve this goal, the delivery system must have targeting capability and a sufficiently long circulatory half-life. The half-life of nanoparticles is often shortened by the immune macrophage system in the liver and spleen. Although some techniques have been used to lessen the detection of the nanoparticles by the macrophages, such as PEGylation and adjustment of size and charge, it takes multiple tests just to find what properties could work for the specific nanocarrier formulation. ${ }^{139}$ Another problem with targeting a certain tissue is the fact that only a small percentage of the nanoparticles that are administered will reach the target tissues.

In addition to general issues with nanoparticles as drug delivery systems, there are specific issues that are often harder to overcome. When treating tumor cells, targeting using the EPR effect has gained significant attention in nanomedicine. The idea that no additional ligands need to 
be added to the nanoparticles makes their use simple and less expensive. The EPR effect, however, does not work for the entire tumor tissue. The leaky vasculature does not extend into the necrotic core of a tumor. Therefore, the nanoparticles tend to aggregate at the periphery of a tumor and do not treat its entirety. Although this treatment can shrink the tumor, it will often not fully eliminate the tumor. The tumor will continue to spread after treatment. ${ }^{140}$ Targeting to certain organs in the body, such as the brain, also has specific issues. The BBB is one of the tightest barriers in the body. The goal of nanodelivery is not only to get through this barrier, but also to deliver the drug to specific cells in the brain. For example, in order to get to targeted neuronal cells, the nanoparticles will have to encounter endothelial cells in the BBB, glial cells, and healthy neuron cells. The nanoparticles need to be able to navigate through and around these cells without damaging them. ${ }^{138}$ Special design will be necessary to overcome the issues associated with the targeted area, in order to enhance the effectiveness of the administered drugs.

The issues do not end once the particle has been specifically delivered to the cells. Nanoparticles with sizes $>20 \mathrm{~nm}$ are normally brought into the cell by endocytosis. Many of these particles are then degraded in lysosomes and no therapeutic effects are achieved. As discussed above, the charge of the nanoparticle can influence the degradation of the nanoparticle once in the endosome/liposome. ${ }^{139}$ These charges, however, are often unfavorable when crossing the biological membranes to make it into the cells. Another area of concern is with the makeup of the nanoparticles. It is important that after the drug has been delivered, the nanoparticle either is eliminated afterward or is biodegradable, especially in the treatment of chronic human diseases. Accumulation of nondegradable nanoparticles in the body over time could lead to unwanted toxicity and cell death.

Engineering nanoparticles that have controlled release properties has another set of challenges. This review mainly discussed polymeric nanoparticles in the section titled "Controlled release". Other types of nanoparticles are less easily manipulated into releasing drugs in a controlled fashion. Liposomes, eg, have a tendency to randomly burst and release the drug in vivo. ${ }^{140}$

One of the leading issues currently facing the continued development of nanoparticle drug delivery systems is the transition from bench to bedside. Targeted nanoparticles have been developed over the past 30 years, yet only a small number of them have reached clinical trials. The FDA has approved no targeted nanoparticles and only seven nanomedicine-based cancer treatments have been approved as of June 2014. ${ }^{140,141}$ This is in part due to the difficulty in reproducing nanoparticle synthesis on a scale needed for commercialization, the lack of understanding regarding how nanosurfaces interact with biosurfaces, the lack of technological platforms necessary to screen large quantities of nanoparticles, and insufficient knowledge about the fate of the nanoparticles once they enter organs, tissues, and cells. ${ }^{140}$

\section{Acknowledgments}

This work was in part supported by Virginia Tech new faculty startup funds, the Hatch Program of the National Institute of Food and Agriculture of the US Department of Agriculture, the Diabetes Action Research and Education Foundation, and supplemental seed funds from the Virginia Tech Center for Drug Discovery, and Virginia Tech's Open Access Subvention Fund (awarded to BX).

\section{Disclosure}

The authors report no conflicts of interest in this work.

\section{References}

1. Strohl WR. The role of natural products in a modern drug discovery program. Drug Discov Today. 2000;5(2):39-41.

2. Manly SP, Padmanabha R, Lowe SE. Natural products or not? How to screen for natural products in the emerging HTS paradigm. Methods Mol Biol. 2002;190:153-168.

3. Lu D, Williams PG, Wang G. Metabolic engineering for the development and manufacturing of pharmaceuticals. In: Tao J, Lin G, Liese A, editors. Biocatalysis for the Pharmaceutical Industry Discovery, Development, and Manufacturing. Singapore: John Wiley \& Sons Asia; 2009:247-271.

4. Khushnud T, Mousa SA. Potential role of naturally derived polyphenols and their nanotechnology delivery in cancer. Mol Biotechnol. 2013;55(1):78-86.

5. Bonifacio BV, Silva PB, Ramos MA, Negri KM, Bauab TM, Chorilli M. Nanotechnology-based drug delivery systems and herbal medicines: a review. Int J Nanomedicine. 2014;9:1-15.

6. Sharma RA, Euden SA, Platton SL, et al. Phase I clinical trial of oral curcumin: biomarkers of systemic activity and compliance. Clin Cancer Res. 2004;10(20):6847-6854.

7. Anand P, Kunnumakkara AB, Newman RA, Aggarwal BB. Bioavailability of curcumin: problems and promises. Mol Pharm. 2007; 4(6):807-818.

8. Manach C, Williamson G, Morand C, Scalbert A, Remesy C. Bioavailability and bioefficacy of polyphenols in humans. I. Review of 97 bioavailability studies. Am J Clin Nutr. 2005;81(1 suppl):230S-242S.

9. Thilakarathna SH, Rupasinghe HP. Flavonoid bioavailability and attempts for bioavailability enhancement. Nutrients. 2013;5(9): 3367-3387.

10. Auffan M, Rose J, Bottero JY, Lowry GV, Jolivet JP, Wiesner MR. Towards a definition of inorganic nanoparticles from an environmental, health and safety perspective. Nat Nanotechnol. 2009;4(10): 634-641.

11. McNeil SE. Nanoparticle therapeutics: a personal perspective. Wiley Interdiscip Rev Nanomed Nanobiotechnol. 2009;1(3):264-271.

12. Dube A, Nicolazzo JA, Larson I. Chitosan nanoparticles enhance the intestinal absorption of the green tea catechins (+)-catechin and (-)-epigallocatechin gallate. Eur J Pharm Sci. 2010;41(2):219-225. 
13. Tan Q, Liu W, Guo C, Zhai G. Preparation and evaluation of quercetinloaded lecithin-chitosan nanoparticles for topical delivery. Int J Nanomedicine. 2011;6:1621-1630.

14. Sanna V, Roggio AM, Siliani S, et al. Development of novel cationic chitosan-and anionic alginate-coated poly(D,L-lactide-co-glycolide) nanoparticles for controlled release and light protection of resveratrol. Int J Nanomedicine. 2012;7:5501-5516.

15. Barhate G, Gautam M, Gairola S, Jadhav S, Pokharkar V. Enhanced mucosal immune responses against tetanus toxoid using novel delivery system comprised of chitosan-functionalized gold nanoparticles and botanical adjuvant: characterization, immunogenicity, and stability assessment. J Pharm Sci. 2014;103(11):3448-3456.

16. Casettari L, Illum L. Chitosan in nasal delivery systems for therapeutic drugs. J Control Release. 2014;190:189-200.

17. Liang J, Li F, Fang Y, et al. Cytotoxicity and apoptotic effects of tea polyphenol-loaded chitosan nanoparticles on human hepatoma HepG2 cells. Mater Sci Eng C Mater Biol Appl. 2014;36:7-13.

18. Samarasinghe RM, Kanwar RK, Kumar K, Kanwar JR. Antiarthritic and chondroprotective activity of Lakshadi Guggul in novel alginateenclosed chitosan calcium phosphate nanocarriers. Nanomedicine (Lond). 2014;9(6):819-837.

19. Leonarduzzi G, Testa G, Sottero B, Gamba P, Poli G. Design and development of nanovehicle-based delivery systems for preventive or therapeutic supplementation with flavonoids. Curr Med Chem 2010;17(1):74-95.

20. Muqbil I, Masood A, Sarkar FH, Mohammad RM, Azmi AS. Progress in nanotechnology based approaches to enhance the potential of chemopreventive agents. Cancers (Basel). 2011;3(1):428-445.

21. Fahr A, van Hoogevest P, May S, Bergstrand N, Leigh ML. Transfer of lipophilic drugs between liposomal membranes and biological interfaces: consequences for drug delivery. Eur J Pharm Sci. 2005;26(3-4):251-265.

22. Yallapu MM, Jaggi M, Chauhan SC. Curcumin nanoformulations: a future nanomedicine for cancer. Drug Discov Today. 2012;17(1-2):71-80.

23. Üner M, Yener G. Importance of solid lipid nanoparticles (SLN) in various administration routes and future perspectives. Int J Nanomedicine. 2007;2(3):289-300.

24. Yallapu MM, Jaggi M, Chauhan SC. Curcumin nanomedicine: a road to cancer therapeutics. Curr Pharm Des. 2013;19(11):1994-2010.

25. Naksuriya O, Okonogi S, Schiffelers RM, Hennink WE. Curcumin nanoformulations: a review of pharmaceutical properties and preclinical studies and clinical data related to cancer treatment. Biomaterials. 2014;35(10):3365-3383

26. Liu Y, Feng N. Nanocarriers for the delivery of active ingredients and fractions extracted from natural products used in traditional Chinese medicine (TCM). Adv Colloid Interface Sci. 2015;221:60-76.

27. Luo Y, Cobb RE, Zhao H. Recent advances in natural product discovery. Curr Opin Biotechnol. 2014;30:230-237.

28. Grynkiewicz G, Ślifirski P. Curcumin and curcuminoids in quest for medicinal status. Acta Biochim Pol. 2012;59(2):201-212.

29. Rothwell JA, Day AJ, Morgan MR. Experimental determination of octanol-water partition coefficients of quercetin and related flavonoids J Agric Food Chem. 2005;53(11):4355-4360.

30. Li J, Liu P, Liu JP, et al. Bioavailability and foam cells permeability enhancement of Salvianolic acid B pellets based on drug-phospholipids complex technique. Eur J Pharm Biopharm. 2013;83(1):76-86.

31. Lee WH, Loo CY, Young PM, Traini D, Mason RS, Rohanizadeh R. Recent advances in curcumin nanoformulation for cancer therapy. Expert Opin Drug Deliv. 2014;11(8):1183-1201.

32. Wang N, Feng Y. Elaborating the role of natural products-induced autophagy in cancer treatment: achievements and artifacts in the state of the art. Biomed Res Int. 2015;2015:934207.

33. Aoki H, Takada Y, Kondo S, Sawaya R, Aggarwal BB, Kondo Y. Evidence that curcumin suppresses the growth of malignant gliomas in vitro and in vivo through induction of autophagy: role of Akt and extracellular signal-regulated kinase signaling pathways. Mol Pharmacol. 2007;72(1):29-39.
34. Zhuang W, Long L, Zheng B, et al. Curcumin promotes differentiation of glioma-initiating cells by inducing autophagy. Cancer Sci. 2012;103(4):684-690.

35. Xiao K, Jiang J, Guan C, et al. Curcumin induces autophagy via activating the AMPK signaling pathway in lung adenocarcinoma cells. J Pharmacol Sci. 2013;123(2):102-109.

36. Morgensztern D, McLeod HL. PI3K/Akt/mTOR pathway as a target for cancer therapy. Anticancer Drugs. 2005;16(8):797-803.

37. Saiki S, Sasazawa Y, Imamichi Y, et al. Caffeine induces apoptosis by enhancement of autophagy via PI3K/Akt/mTOR/p70S6K inhibition. Autophagy. 2011;7(2):176-187.

38. Khan KH, Yap TA, Yan L, Cunningham D. Targeting the PI3K-AKTmTOR signaling network in cancer. Chin J Cancer. 2013;32(5): $253-265$.

39. Wang M, Yu T, Zhu C, et al. Resveratrol triggers protective autophagy through the ceramide/Akt/mTOR pathway in melanoma B16 cells. Nutr Cancer. 2014;66(3):435-440.

40. Wang G, Wang JJ, To TS, Zhao HF, Jung W. Role of SIRT1-mediated mitochondrial and Akt pathways in glioblastoma cell death induced by Cotinus coggygria flavonoid nanoliposomes. Int $J$ Nanomedicine. 2015;10:5005-5023.

41. Di Pietro A, Dayan G, Conseil G, et al. P-glycoprotein-mediated resistance to chemotherapy in cancer cells: using recombinant cytosolic domains to establish structure-function relationships. Braz J Med Biol Res. 1999;32(8):925-939.

42. Borska S, Chmielewska M, Wysocka T, Drag-Zalesinska M, Zabel M, Dziegiel P. In vitro effect of quercetin on human gastric carcinoma: targeting cancer cells death and MDR. Food Chem Toxicol. 2012;50(9):3375-3383.

43. Nguyen H, Zhang S, Morris ME. Effect of flavonoids on MRP1-mediated transport in Panc-1 cells. J Pharm Sci. 2003;92(2):250-257.

44. Chang H, Chen B. Inhibition of lung cancer cells A549 and H460 by curcuminoid extracts and nanoemulsions prepared from Curcuma longa Linnaeus. Int J Nanomedicine. 2015;10:5059-5080.

45. Kirst HA. Developing new antibacterials through natural product research. Expert Opin Drug Discov. 2013;8(5):479-493.

46. Ouattara B, Simard RE, Holley RA, Piette GJ, Bégin A. Antibacterial activity of selected fatty acids and essential oils against six meat spoilage organisms. Int J Food Microbiol. 1997;37(2-3):155-162.

47. Sharma G, Raturi K, Dang S, Gupta S, Gabrani R. Combinatorial antimicrobial effect of curcumin with selected phytochemicals on Staphylococcus epidermidis. J Asian Nat Prod Res. 2014;16(5):535-541.

48. Lv F, Liang H, Yuan Q, Li C. In vitro antimicrobial effects and mechanism of action of selected plant essential oil combinations against four foodrelated microorganisms. Food Res Intern. 2011;44:3057-3064.

49. Gill AO, Holley RA. Mechanisms of bactericidal action of cinnamaldehyde against Listeria monocytogenes and of eugenol against L. monocytogenes and Lactobacillus sakei. Appl Environ Microbiol. 2004;70(10):5750-5755.

50. Nair HB, Sung B, Yadav VR, Kannappan R, Chaturvedi MM, Aggarwal BB. Delivery of antiinflammatory nutraceuticals by nanoparticles for the prevention and treatment of cancer. Biochem Pharmacol. 2010;80(12):1833-1843.

51. Prasad S, Phromnoi K, Yadav VR, Chaturvedi MM, Aggarwal BB. Targeting inflammatory pathways by flavonoids for prevention and treatment of cancer. Planta Med. 2010;76(11):1044-1063.

52. Bala I, Bhardwaj V, Hariharan S, Kharade SV, Roy N, Ravi Kumar MN. Sustained release nanoparticulate formulation containing antioxidantellagic acid as potential prophylaxis system for oral administration. J Drug Target. 2006;14(1):27-34.

53. Takahashi M, Uechi S, Takara K, Asikin Y, Wada K. Evaluation of an oral carrier system in rats: bioavailability and antioxidant properties of liposome-encapsulated curcumin. J Agric Food Chem. 2009;57(19):9141-9146.

54. Felice F, Zambito Y, Belardinelli E, et al. Delivery of natural polyphenols by polymeric nanoparticles improves the resistance of endothelial progenitor cells to oxidative stress. Eur J Pharm Sci. 2013;50(3-4):393-399. 
55. Rameshkumar A, Sivasudha T, Jeyadevi R, et al. In vitro antioxidant and antimicrobial activities of Merremia emarginata using thio glycolic acid-capped cadmium telluride quantum dots. Colloids Surf B Biointerfaces. 2013;101:74-82.

56. Zu Y, Wu W, Zhao X, et al. Enhancement of solubility, antioxidant ability and bioavailability of taxifolin nanoparticles by liquid antisolvent precipitation technique. Int J Pharm. 2014;471(1-2):366-376.

57. Jørgensen LV, Madsen HL, Thomsen MK, Dragsted LO, Skibsted LH. Regeneration of phenolic antioxidants from phenoxyl radicals: an ESR and electrochemical study of antioxidant hierarchy. Free Radic Res. 1999;30(3):207-220.

58. Weber WM, Hunsaker LA, Abcouwer SF, Deck LM, Vander Jagt DL. Anti-oxidant activities of curcumin and related enones. Bioorg Med Chem. 2005;13(11):3811-3820.

59. Zhao GR, Zhang HM, Ye TX, et al. Characterization of the radical scavenging and antioxidant activities of danshensu and salvianolic acid B. Food Chem Toxicol. 2008;46(1):73-81.

60. Xue M, Zhang L, Yang M, et al. Berberine-loaded solid lipid nanoparticles are concentrated in the liver and ameliorate hepatosteatosis in $\mathrm{db} /$ $\mathrm{db}$ mice. Int J Nanomedicine. 2015;10:5049-5057.

61. Abdelwahab SI, Sheikh BY, Taha MM, et al. Thymoquinone-loaded nanostructured lipid carriers: preparation, gastroprotection, in vitro toxicity, and pharmacokinetic properties after extravascular administration. Int J Nanomedicine. 2013;8:2163-2172.

62. Peng LH, Xu SY, Shan YH, et al. Sequential release of salidroside and paeonol from a nanosphere-hydrogel system inhibits ultraviolet B-induced melanogenesis in guinea pig skin. Int J Nanomedicine. 2014;9: 1897-1908.

63. Celia C, Trapasso E, Locatelli M, et al. Anticancer activity of liposomal bergamot essential oil (BEO) on human neuroblastoma cells. Colloids Surf B Biointerfaces. 2013;112:548-553.

64. Pund S, Borade G, Rasve G. Improvement of anti-inflammatory and anti-angiogenic activity of berberine by novel rapid dissolving nanoemulsifying technique. Phytomedicine. 2014;21(3):307-314.

65. Ding SM, Zhang ZH, Song J, Cheng XD, Jiang J, Jia XB. Enhanced bioavailability of apigenin via preparation of a carbon nanopowder solid dispersion. Int J Nanomedicine. 2014;9:2327-2333.

66. Kakkar V, Singh S, Singla D, Kaur IP. Exploring solid lipid nanoparticles to enhance the oral bioavailability of curcumin. Mol Nutr Food Res. 2011;55(3):495-503.

67. Xie X, Tao Q, Zou Y, et al. PLGA nanoparticles improve the oral bioavailability of curcumin in rats: characterizations and mechanisms. J Agric Food Chem. 2011;59(17):9280-9289.

68. Shoba G, Joy D, Joseph T, Majeed M, Rajendran R, Srinivas PS. Influence of piperine on the pharmacokinetics of curcumin in animals and human volunteers. Planta Med. 1998;64(4):353-356.

69. Lambert JD, Hong J, Kim DH, Mishin VM, Yang CS. Piperine enhances the bioavailability of the tea polyphenol (-)-epigallocatechin-3-gallate in mice. J Nutr. 2004;134(8):1948-1952.

70. Surh YJ. Anti-tumor promoting potential of selected spice ingredients with antioxidative and anti-inflammatory activities: a short review. Food Chem Toxicol. 2002;40(8):1091-1097.

71. Ono K, Hasegawa K, Naiki H, Yamada M. Curcumin has potent antiamyloidogenic effects for Alzheimer's beta-amyloid fibrils in vitro. J Neurosci Res. 2004;75(6):742-750.

72. Maheshwari RK, Singh AK, Gaddipati J, Srimal RC. Multiple biological activities of curcumin: a short review. Life Sci. 2006;78(18):2081-2087.

73. Shen H, Hu X, Szymusiak M, Wang ZJ, Liu Y. Orally administered nanocurcumin to attenuate morphine tolerance: comparison between negatively charged PLGA and partially and fully PEGylated nanoparticles. Mol Pharm. 2013;10(12):4546-4551.

74. Gupta SC, Patchva S, Aggarwal BB. Therapeutic roles of curcumin: lessons learned from clinical trials. AAPS J. 2013;15(1):195-218.

75. Wahlstrom B, Blennow G. A study on the fate of curcumin in the rat. Acta Pharmacol Toxicol (Copenhagen). 1978;43(2):86-92.
76. Narayanan NK, Nargi D, Randolph C, Narayanan BA. Liposome encapsulation of curcumin and resveratrol in combination reduces prostate cancer incidence in PTEN knockout mice. Int $J$ Cancer. 2009;125(1):1-8.

77. Li R, Qiao X, Li Q, et al. Metabolic and pharmacokinetic studies of curcumin, demethoxycurcumin and bisdemethoxycurcumin in mice tumor after intragastric administration of nanoparticle formulations by liquid chromatography coupled with tandem mass spectrometry. J Chromatogr B Analyt Technol Biomed Life Sci. 2011;879(26):2751-2758.

78. Bisht S, Mizuma M, Feldmann G, et al. Systemic administration of polymeric nanoparticle-encapsulated curcumin (NanoCurc) blocks tumor growth and metastases in preclinical models of pancreatic cancer. Mol Cancer Ther. 2010;9(8):2255-2264.

79. Chun YS, Bisht S, Chenna V, et al. Intraductal administration of a polymeric nanoparticle formulation of curcumin (NanoCurc) significantly attenuates incidence of mammary tumors in a rodent chemical carcinogenesis model: implications for breast cancer chemoprevention in at-risk populations. Carcinogenesis. 2012;33(11): 2242-2249.

80. Bhawana, Basniwal RK, Buttar HS, Jain VK, Jain N. Curcumin nanoparticles: preparation, characterization, and antimicrobial study. J Agric Food Chem. 2011;59(5):2056-2061.

81. Rajasekaran M, Annaraj J. A lucid build-up of nanostructured curcumin, quercetin and their interaction with DNA. J Nanosci Nanotechnol. 2014;14(7):4874-4879.

82. Singh A, Ahmad I, Akhter S, et al. Nanocarrier based formulation of Thymoquinone improves oral delivery: stability assessment, in vitro and in vivo studies. Colloids Surf B Biointerfaces. 2013;102:822-832.

83. Bhatta RS, Chandasana H, Chhonker YS, et al. Mucoadhesive nanoparticles for prolonged ocular delivery of natamycin: in vitro and pharmacokinetics studies. Int J Pharm. 2012;432(1-2):105-112.

84. Li Y, Sun S, Chang Q, et al. A strategy for the improvement of the bioavailability and antiosteoporosis activity of BCS IV flavonoid glycosides through the formulation of their lipophilic aglycone into nanocrystals. Mol Pharm. 2013;10(7):2534-2542.

85. Tran TH, Guo Y, Song D, Bruno RS, Lu X. Quercetin-containing self-nanoemulsifying drug delivery system for improving oral bioavailability. J Pharm Sci. 2014;103(3):840-852.

86. Siddiqui IA, Adhami VM, Ahmad N, Mukhtar H. Nanochemoprevention: sustained release of bioactive food components for cancer prevention. Nutr Cancer. 2010;62(7):883-890.

87. Singh M, Bhatnagar P, Srivastava AK, Kumar P, Shukla Y, Gupta KC. Enhancement of cancer chemosensitization potential of cisplatin by tea polyphenols poly(lactide-co-glycolide) nanoparticles. J Biomed Nanotechnol. 2011;7(1):202.

88. Gohulkumar M, Gurushankar K, Rajendra Prasad N, Krishnakumar N. Enhanced cytotoxicity and apoptosis-induced anticancer effect of silibinin-loaded nanoparticles in oral carcinoma (KB) cells. Mater Sci Eng C Mater Biol Appl. 2014;41:274-282.

89. Majumdar D, Jung KH, Zhang H, et al. Luteolin nanoparticle in chemoprevention: in vitro and in vivo anticancer activity. Cancer Prev Res. 2014;7(1):65-73.

90. Bhardwaj RK, Glaeser H, Becquemont L, Klotz U, Gupta SK, Fromm MF. Piperine, a major constituent of black pepper, inhibits human P-glycoprotein and CYP3A4. J Pharmacol Exp Ther. 2002;302(2):645-650.

91. Al-Shawi MK, Omote H. The remarkable transport mechanism of P-glycoprotein: a multidrug transporter. J Bioenerg Biomembr. 2005;37(6):489-496.

92. Gupta V, Aseh A, Rios CN, Aggarwal BB, Mathur AB. Fabrication and characterization of silk fibroin-derived curcumin nanoparticles for cancer therapy. Int J Nanomedicine. 2009;4:115-122.

93. Testa G, Gamba P, Badilli U, et al. Loading into nanoparticles improves quercetin's efficacy in preventing neuroinflammation induced by oxysterols. PLoS One. 2014;9(5):e96795. 
94. Huang S, Chang SJ, Yang M, Chen JJ, Chang WH. Nanoscale hepatoprotective herbal decoction attenuates hepatic stellate cell activity and chloroform-induced liver damage in mice. Int J Nanomedicine. 2011;6:1365-1371.

95. Lin CH, Al-Suwayeh SA, Hung CF, Chen CC, Fang JY. Camptothecinloaded liposomes with alpha-melanocyte-stimulating hormone enhance cytotoxicity toward and cellular uptake by melanomas: an application of nanomedicine on natural product. J Tradit Complement Med. 2013;3(2):102-109.

96. Shelton MC, Posey-Dowty JD, Lingerfelt L, Kirk SK, Klein S, Edgar KJ. Enhanced dissolution of poorly soluble drugs from solid dispersions in carboxymethylcellulose acetate butyrate matrices. In: Edgar KJ, Heinze T, Buchanan CM, editors. Polysaccharide Materials. Performance by Design. Washington, DC: ACS; 2009:93-113.

97. Li B, Harich K, Wegiel L, Taylor LS, Edgar KJ. Stability and solubility enhancement of ellagic acid in cellulose ester solid dispersions. Carbohydr Polym. 2013;92(2):1443-1450.

98. Li B, Konecke S, Harich K, Wegiel L, Taylor LS, Edgar KJ. Solid dispersion of quercetin in cellulose derivative matrices influences both solubility and stability. Carbohydr Polym. 2013;92(2):2033-2040.

99. Li B, Konecke S, Wegiel LA, Taylor LS, Edgar KJ. Both solubility and chemical stability of curcumin are enhanced by solid dispersion in cellulose derivative matrices. Carbohydr Polymers. 2013;98(1):1108-1116

100. Abdulkarim MF, Abdullah GZ, Chitneni M, et al. Topical piroxicam in vitro release and in vivo anti-inflammatory and analgesic effects from palm oil esters-based nanocream. Int J Nanomedicine. 2010;5:915-924.

101. Ascenso A, Pinho S, Eleutério C, et al. Lycopene from tomatoes: vesicular nanocarrier formulations for dermal delivery. J Agric Food Chem. 2013;61(30):7284-7293.

102. Bennet D, Kang SC, Gang J, Kim S. Photoprotective effects of apple peel nanoparticles. Int J Nanomedicine. 2014;9:93-108.

103. Panyam J, Labhasetwar V. Biodegradable nanoparticles for drug and gene delivery to cells and tissue. Adv Drug Deliv Rev. 2003;55(3):329-347.

104. Sou K, Goins B, Takeoka S, Tsuchida E, Phillips WT. Selective uptake of surface-modified phospholipid vesicles by bone marrow macrophages in vivo. Biomaterials. 2007;28(16):2655-2666.

105. Sou K, Inenaga S, Takeoka S, Tsuchida E. Loading of curcumin into macrophages using lipid-based nanoparticles. Int J Pharm. 2008;352(1-2):287-293.

106. Yallapu MM, Othman SF, Curtis ET, et al. Curcumin-loaded magnetic nanoparticles for breast cancer therapeutics and imaging applications Int J Nanomedicine. 2012;7:1761-1779.

107. Li L, Xiang D, Shigdar S, et al. Epithelial cell adhesion molecule aptamer functionalized PLGA-lecithin-curcumin-PEG nanoparticles for targeted drug delivery to human colorectal adenocarcinoma cells. Int J Nanomedicine. 2014;9:1083-1096.

108. Garg A, Singh S. Targeting of eugenol-loaded solid lipid nanoparticles to the epidermal layer of human skin. Nanomedicine (Lond). 2014;9(8):1223-1238.

109. Huang W, Wang X, Shi C, et al. Fine-tuning vitamin E-containing telodendrimers for efficient delivery of gambogic acid in colon cancer treatment. Mol Pharm. 2015;12(4):1216-1229.

110. Barreto AC, Santiago VR, Freire RM, et al. Magnetic nanosystem for cancer therapy using oncocalyxone a, an antitomour secondary metabolite isolated from a Brazilian plant. Int $J$ Mol Sci. 2013;14(9):18269-18283.

111. El-Gogary RI, Rubio N, Wang JT, et al. Polyethylene glycol conjugated polymeric nanocapsules for targeted delivery of quercetin to folate-expressing cancer cells in vitro and in vivo. ACS Nano. 2014;8(2):1384-1401.

112. Loureiro JA, Gomes B, Coelho MA, do Carmo Pereira M, Rocha S. Targeting nanoparticles across the blood-brain barrier with monoclonal antibodies. Nanomedicine (Lond). 2014;9(5):709-722.
113. Sheik DA, Brooks L, Frantzen K, Dewhurst S, Yang J. Inhibition of the enhancement of infection of human immunodeficiency virus by semen-derived enhancer of virus infection using amyloid-targeting polymeric nanoparticles. ACS Nano. 2015;9(2):1829-1836.

114. Dreaden EC, Austin LA, Mackey MA, El-Sayed MA. Size matters: gold nanoparticles in targeted cancer drug delivery. Ther Deliv. 2012; 3(4):457-478.

115. Panyam J, Zhou WZ, Prabha S, Sahoo SK, Labhasetwar V. Rapid endo-lysosomal escape of poly (D,L-lactide-co-glycolide) nanoparticles: implications for drug and gene delivery. FASEB J. 2002;16(10):1217-1226.

116. Megill A, Lee T, DiBattista AM, et al. A tetra(ethylene glycol) derivative of benzothiazole aniline enhances Ras-mediated spinogenesis. J Neurosci. 2013;33(22):9306-9318.

117. Fang L, Gou S, Liu X, Cao F, Cheng L. Design, synthesis and antiAlzheimer properties of dimethylaminomethyl-substituted curcumin derivatives. Bioorg Med Chem Lett. 2014;24(1):40-43.

118. Murphy MP, Smith RA. Drug delivery to mitochondria: the key to mitochondrial medicine. Adv Drug Deliv Rev. 2000;41(2):235-250.

119. Bouarab L, Maherani B, Kheirolomoom A, et al. Influence of lecithinlipid composition on physico-chemical properties of nanoliposomes loaded with a hydrophobic molecule. Colloids Surf B Biointerfaces. 2014;115:197-204.

120. Cai H, Wen X, Wen L, et al. Enhanced local bioavailability of single or compound drugs delivery to the inner ear through application of PLGA nanoparticles via round window administration. Int J Nanomedicine. 2014;9:5591-5601

121. Bisht S, Feldmann G, Soni S, et al. Polymeric nanoparticle-encapsulated curcumin ("nanocurcumin"): a novel strategy for human cancer therapy. J Nanobiotechnology. 2007;5:3.

122. Gugulothu D, Kulkarni A, Patravale V, Dandekar P. pH-sensitive nanoparticles of curcumin-celecoxib combination: evaluating drug synergy in ulcerative colitis model. J Pharm Sci. 2014;103(2):687-696.

123. Li F, Li X, Li B. Preparation of magnetic polylactic acid microspheres and investigation of its releasing property for loading curcumin. J Magn Magn Mater. 2011;323(22):2770-2775.

124. Tiyaboonchai W, Tungpradit W, Plianbangchang P. Formulation and characterization of curcuminoids loaded solid lipid nanoparticles. Int J Pharm. 2007;337(1-2):299-306.

125. Rocha S, Generalov R, Pereira Mdo C, Peres I, Juzenas P, Coelho MA. Epigallocatechin gallate-loaded polysaccharide nanoparticles for prostate cancer chemoprevention. Nanomedicine (Lond). 2011;6(1):79-87.

126. Gomes C, Moreira RG, Castell-Perez E. Poly (DL-lactide-co-glycolide) (PLGA) nanoparticles with entrapped trans-cinnamaldehyde and eugenol for antimicrobial delivery applications. J Food Sci. 2011; 76(2):N16-N24.

127. Bhushan S, Kakkar V, Pal HC, et al. Enhanced anticancer potential of encapsulated solid lipid nanoparticles of TPD: a novel triterpenediol from Boswellia serrata. Mol Pharm. 2013;10(1):225-235.

128. Kumari A, Yadav SK, Pakade YB, Singh B, Yadav SC. Development of biodegradable nanoparticles for delivery of quercetin. Colloids Surf B Biointerfaces. 2010;80(2):184-192.

129. Date AA, Nagarsenker MS, Patere S, et al. Lecithin-based novel cationic nanocarriers (Leciplex) II: improving therapeutic efficacy of quercetin on oral administration. Mol Pharm. 2011;8(3):716-726.

130. He Q, Zhang J, Chen F, Guo L, Zhu Z, Shi J. An anti-ROS/hepatic fibrosis drug delivery system based on salvianolic acid B loaded mesoporous silica nanoparticles. Biomaterials. 2010;31(30):7785-7796.

131. Cirpanli Y, Bilensoy E, Dogan AL, Calis S. Development of polymeric and cyclodextrin nanoparticles for camptothecin delivery. $J$ Control Release. 2010;148(1):e21-e23.

132. Silva LM, Hill LE, Figueiredo E, Gomes CL. Delivery of phytochemicals of tropical fruit by-products using poly (DL-lactide-co-glycolide) (PLGA) nanoparticles: synthesis, characterization, and antimicrobial activity. Food Chem. 2014;165:362-370. 
133. Fomina N, McFearin C, Sermsakdi M, Edigin O, Almutairi A. UV and near-IR triggered release from polymeric nanoparticles. J Am Chem Soc. 2010;132(28):9540-9542.

134. Di J, Price J, Gu X, Jiang X, Jing Y, Gu Z. Ultrasound-triggered regulation of blood glucose levels using injectable nano-network. Adv Healthc Mater. 2014;3(6):811-816.

135. Jain KK. Nanobiotechnology-based strategies for crossing the bloodbrain barrier. Nanomedicine (Lond). 2012;7(8):1225-1233.

136. Muller RH, Gohla S, Keck CM. State of the art of nanocrystals - special features, production, nanotoxicology aspects and intracellular delivery. Eur J Pharm Biopharm. 2011;78(1):1-9.

137. Bernkop-Schnürch A. Nanocarrier systems for oral drug delivery: do we really need them? Eur J Pharm Sci. 2013;49(2):272-277.
138. Krol S. Challenges in drug delivery to the brain: nature is against us. J Control Release. 2012;164(2):145-155.

139. De Jong WH, Borm PJ. Drug delivery and nanoparticles: applications and hazards. Int J Nanomedicine. 2008;3(2):133-149.

140. Kamaly N, Xiao Z, Valencia PM, Radovic-Moreno AF, Farokhzad OC. Targeted polymeric therapeutic nanoparticles: design, development and clinical translation. Chem Soc Rev. 2012;41(7):2971-3010.

141. Pillai G. Nanomedicines for cancer therapy: an update of FDA approved and those under various stages of development. SOJ Pharm Pharm Sci. 2014;1(2):13.

\section{Publish your work in this journal}

The International Journal of Nanomedicine is an international, peerreviewed journal focusing on the application of nanotechnology in diagnostics, therapeutics, and drug delivery systems throughout the biomedical field. This journal is indexed on PubMed Central, MedLine, CAS, SciSearch ${ }^{\circledR}$, Current Contents ${ }^{\circledR} /$ Clinical Medicine,
Journal Citation Reports/Science Edition, EMBase, Scopus and the Elsevier Bibliographic databases. The manuscript management system is completely online and includes a very quick and fair peer-review system, which is all easy to use. Visit http://www.dovepress.com/ testimonials.php to read real quotes from published authors. 